\title{
مصر وحلف بغداد
}

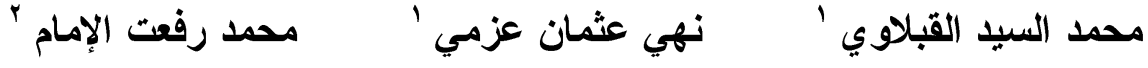 \\ ' كلية السياحة و الفنادق، جامعة مدينة السادات \\ كلية الآداب، جامعة دمنهور
}

الملخص

كان لمصر بعد ثورة با بوليو 90 ام دور بارز في التصدي لمشاريع الأحلاف العسكرية الغربية

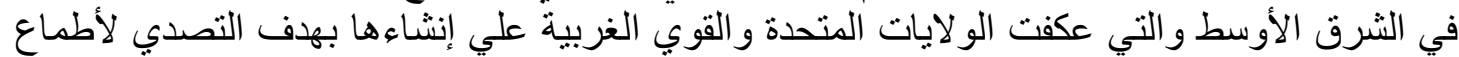

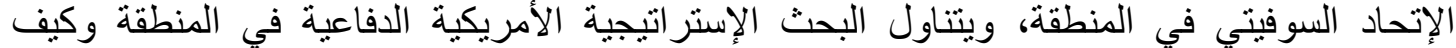

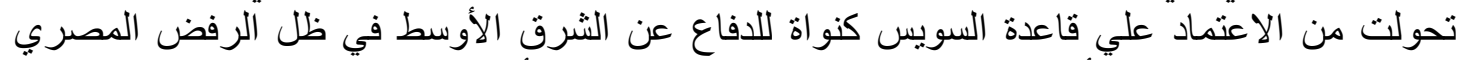

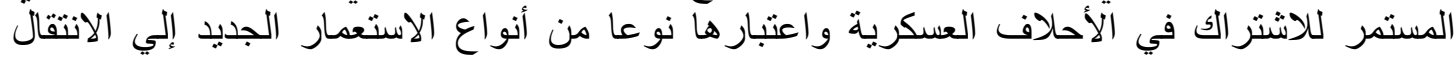

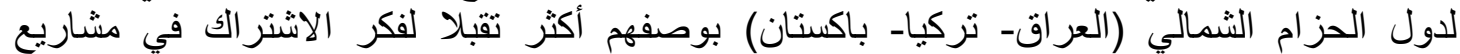

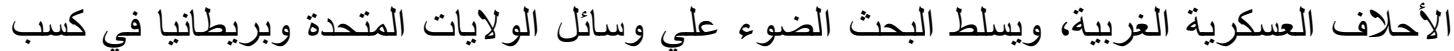

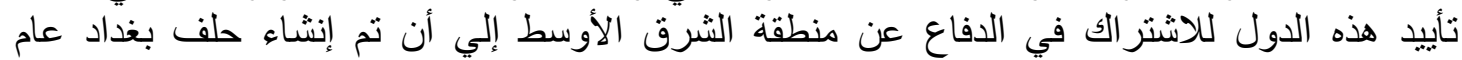

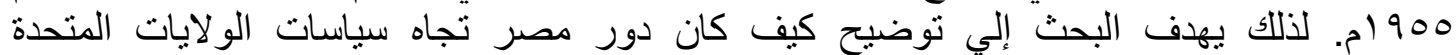
وبريطانيا في المنطقة وكيف تصرفت مصر بنفسها للتصدي لحلف بغداد من خلان تول توجيه النداء التوات

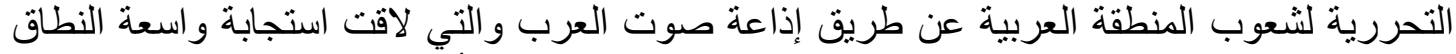

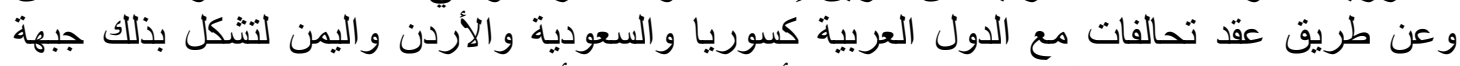

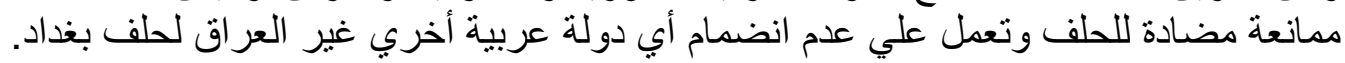
الكلمات الدالة: قاعدة السويس، حلف بغداد، الثرق الأوسط، مصر.

مقدمة

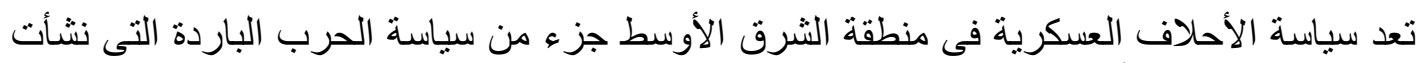

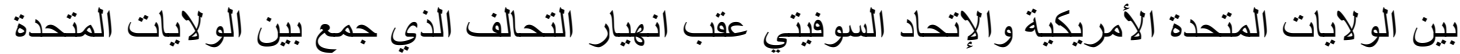

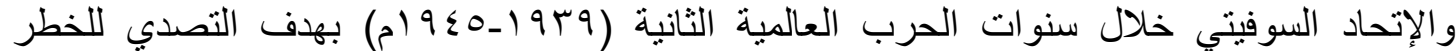

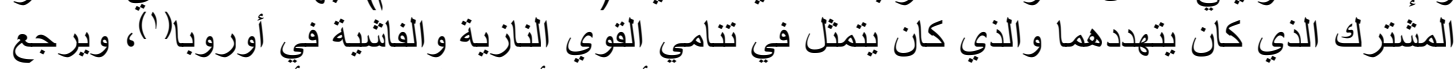

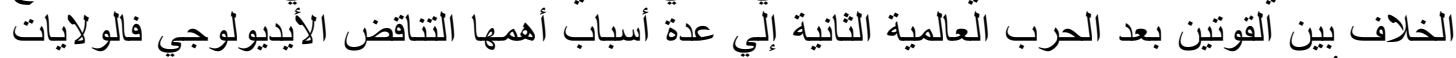

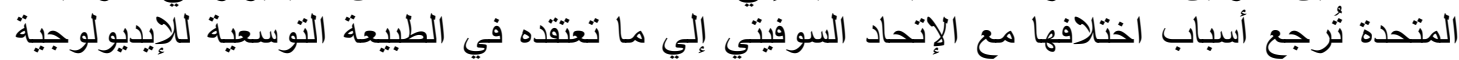

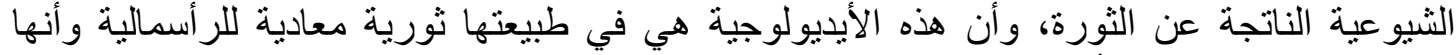

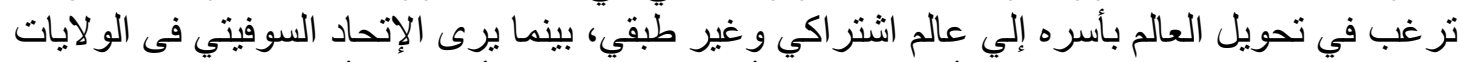

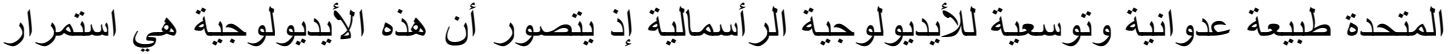
للإستغلالية والتي دفعت إلي نهب المناطق الغنية بالموارد الأولية وتخضعها لهيمنة النظام الرأسمالي التئي

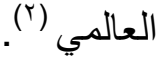

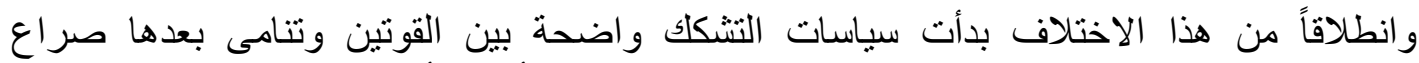

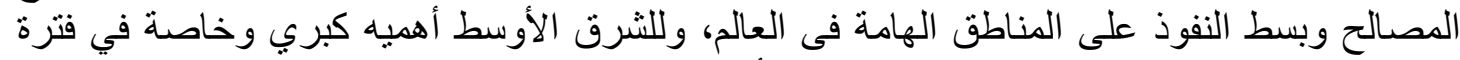

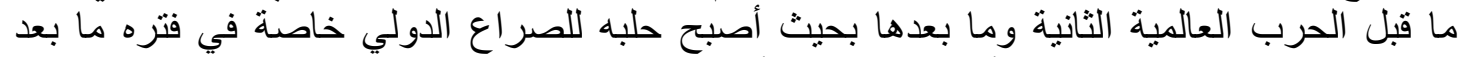

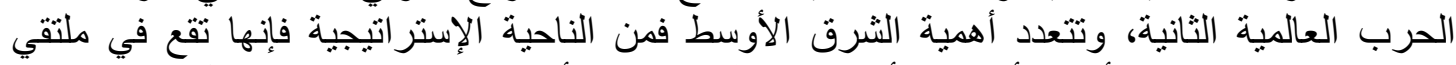

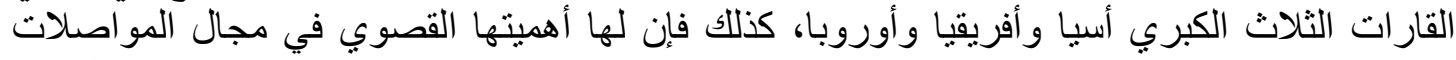

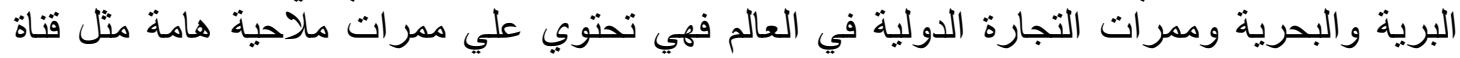

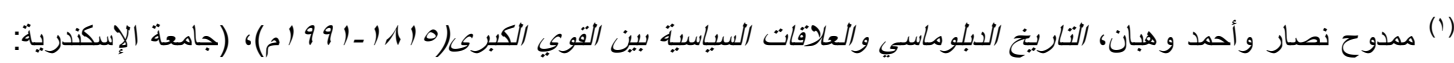

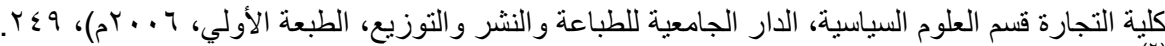

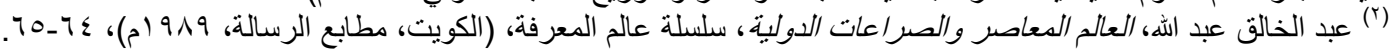
Stanley Hoffmann, Primacy of World Order: American Foreign Policy since the cold War, (U.S, McGrew publishing, 1980), 253. 
السويس ومضائق باب المندب وهرمز وكذلك مضائق البحر الأسود " الدردنيل و البسفور" كما أن أن أن أنيا

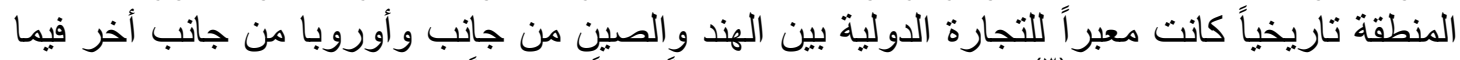

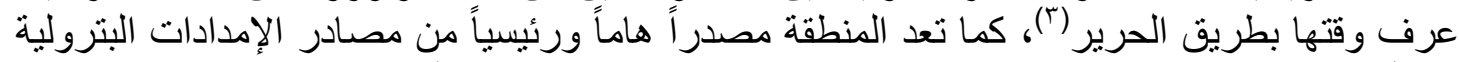
إلي أوروبا و الولايات المتحدة وتمثل المصدر الرئيسي للطاقة لإقتصاد أوروبا الغربية وتقدي الغدر واردات

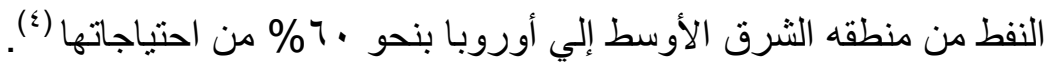

كذلك فمن الناحية الأمنية فإن منطقة الثرق الأوسط وثثقة الصلة بالأمن العالمي و النظام الدولي

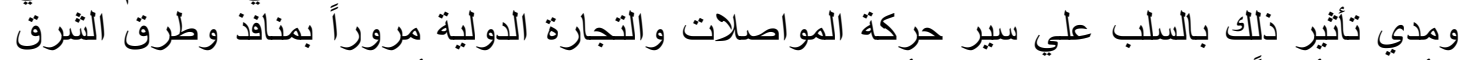

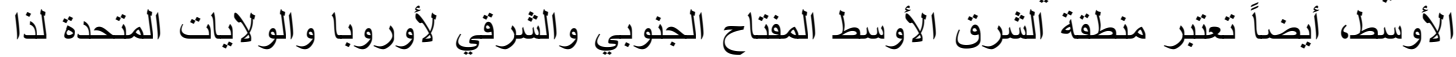

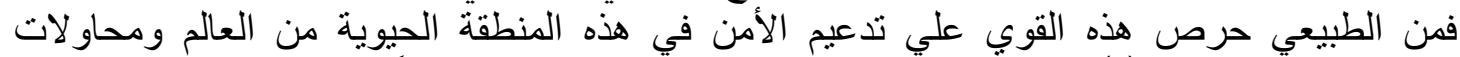

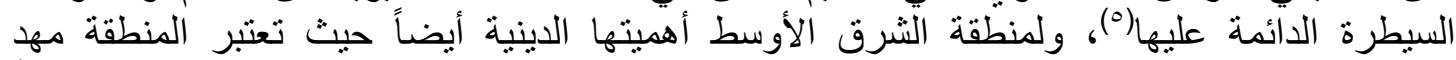

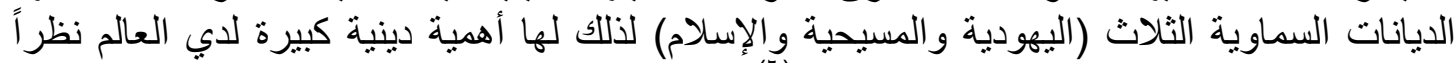

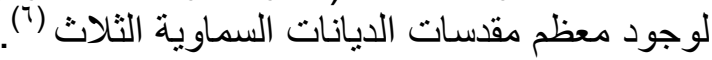

وبالنظر إلي تعدد أهمية المنطقة فكان من الطبيعي أن تكون منطقة الثرق الأوسط محل صر اعات

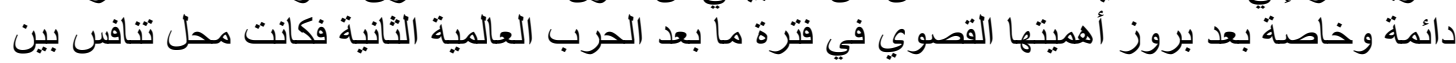

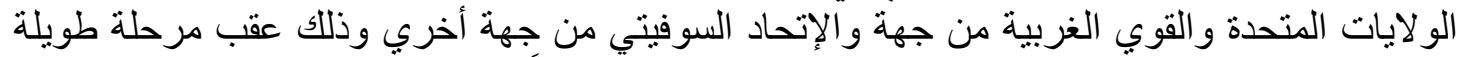

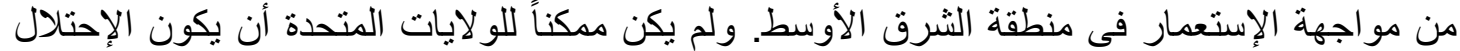
أحد سبل فرض نفوذها في المنطقة لذا كان البديل الذي يضمن ذلإنك هو سياسة الأحلاف العسكرية،

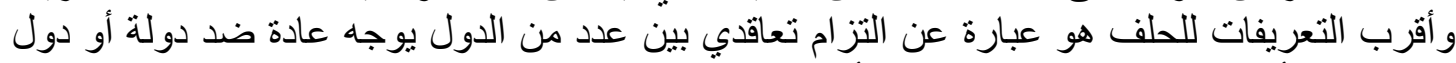

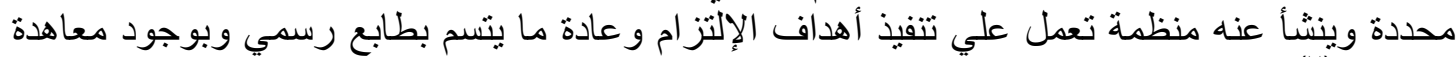
أو إتفاق (V)

\section{() سباسات الولايات المتحدة في منطقة الثرق الأوسط}

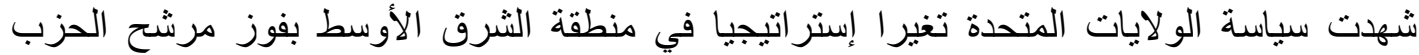

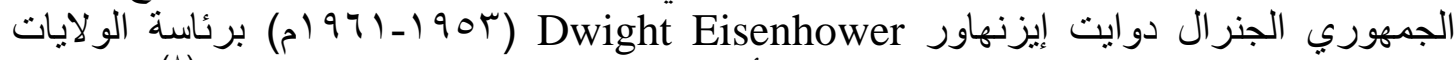

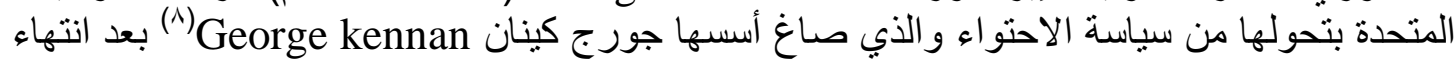

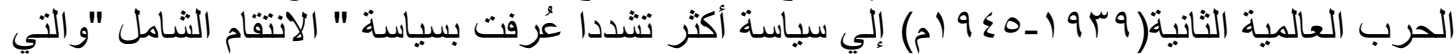

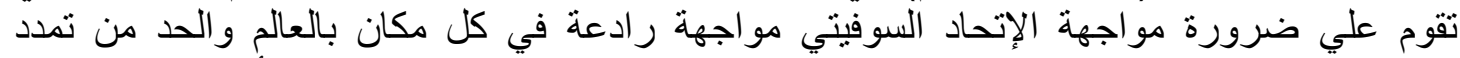

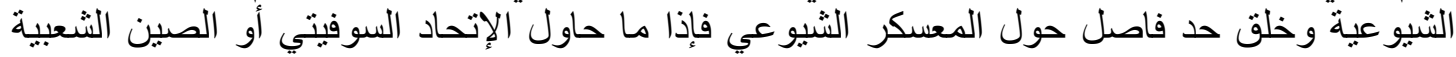

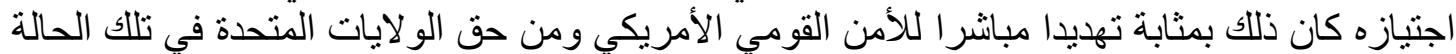

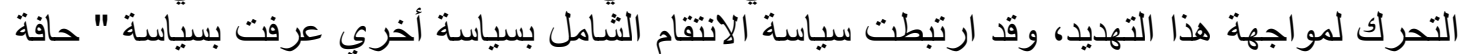

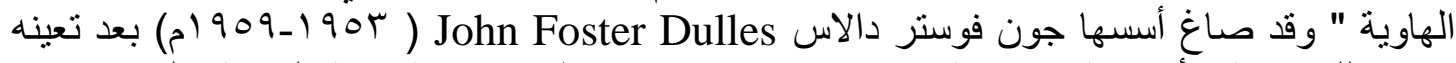

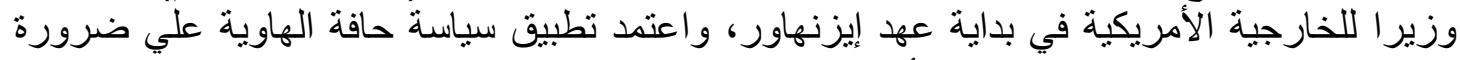
تطويق الإتحاد السوفيتي بحزام من الأحلاف العسكرية لإمكان تطبيق سياسة الانتقام الثامل وسيكون فئن

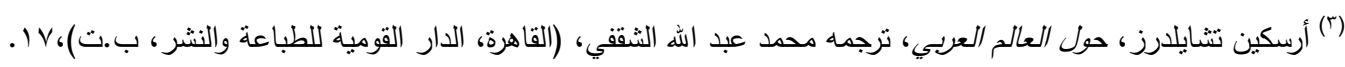
${ }^{\left({ }^{(}\right)}$Philip W. Thayer, Tension in the Middle East, (Baltimore U.S, john Hopkins press, 1958), 6.

${ }^{\left({ }^{\circ}\right)}$ John S. badeau, the American approach to the Arab world, (New York, Harper and Row publishing, 1968), 20-21.

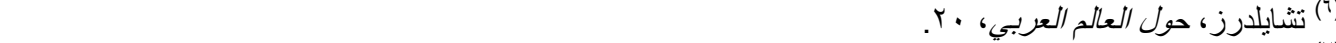

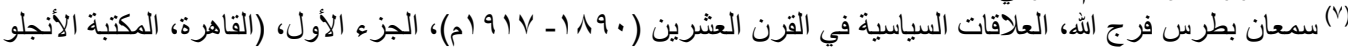

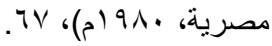

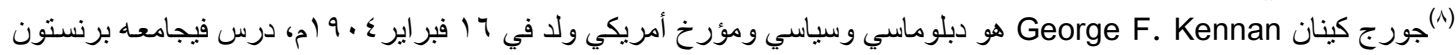

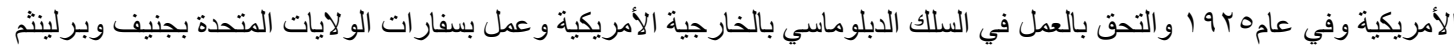

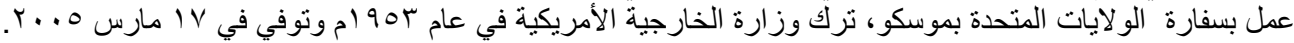
Department of state web site, access Date (January 18, 2016). WWW.m.state.gov 
تكوين الأحلاف من الدول الموالية للولايات المتحدة والقوي الغربية حول العالم ويتحقق ذلك بالعمل

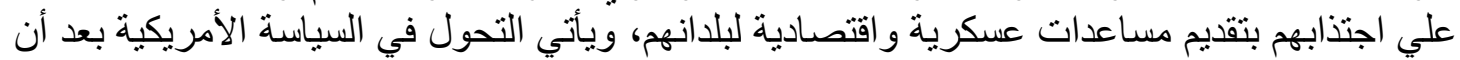

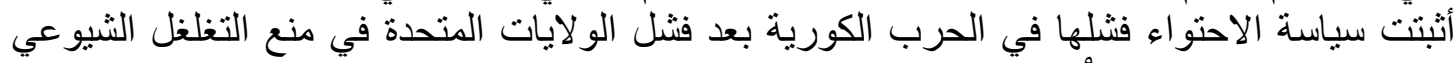
في شبة الجزيرة الكورية.

\section{r ) مصر وموقفها من السباسات الأمريكبة في منطقة الثرق الأوسط}

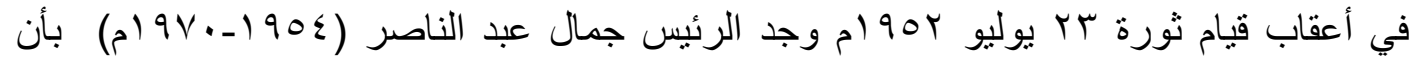

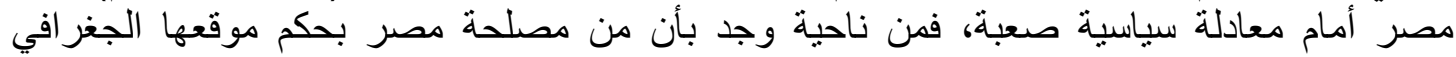

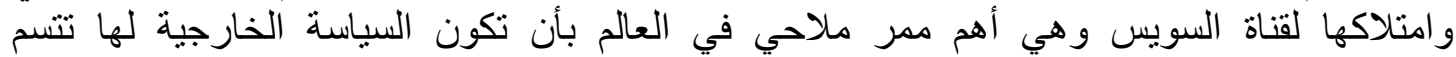

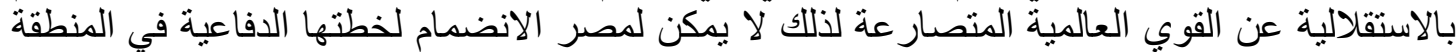

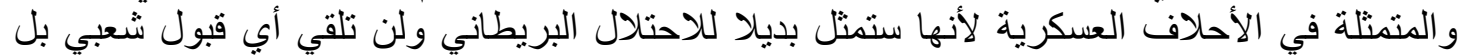

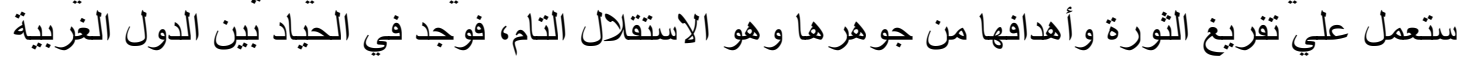

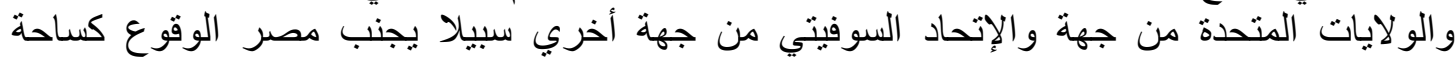

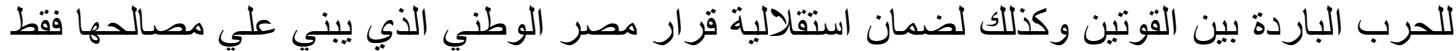

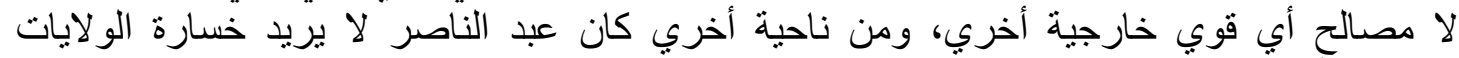

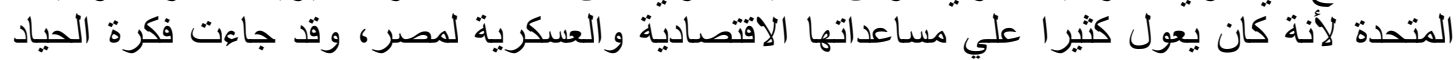

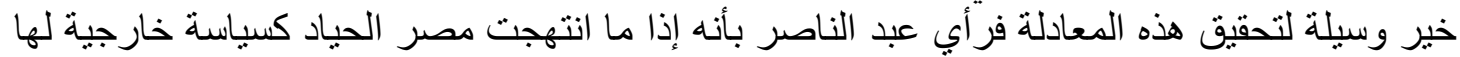

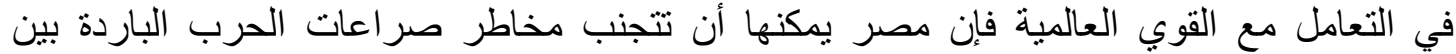
الولايات المتحدة والإتحاد السوفيتي وفي نفس الوقت بمكنها الاستفادة من كلاهما اقتصاديا ولتيات وعسكريا،

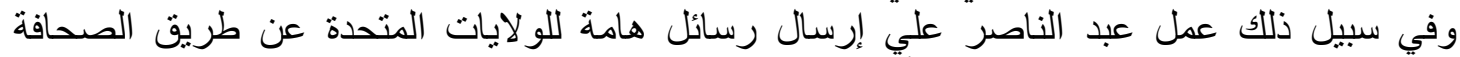
والإذاعة وكذلك عملاء المخابرات الأمريكية في مصر بالإضافة إلي الرسائل الرسمية التي التي حملها التها

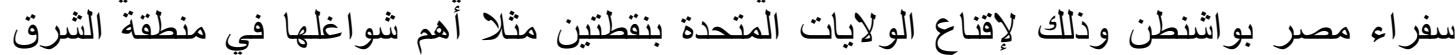

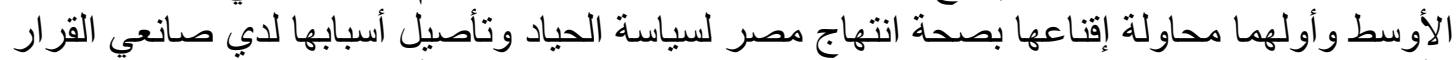

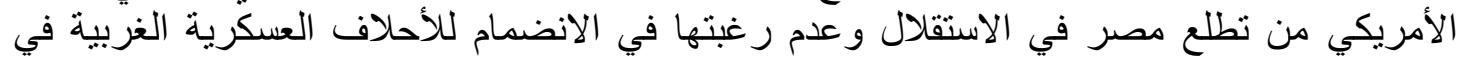

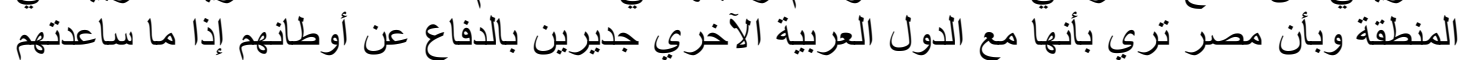

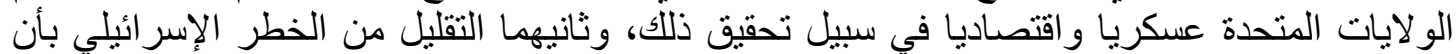

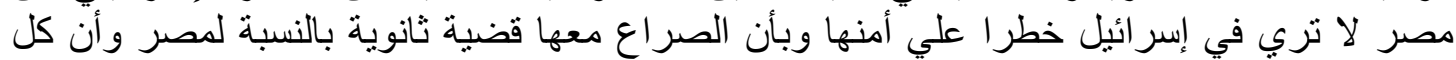

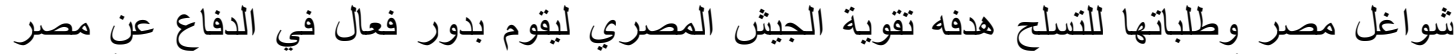

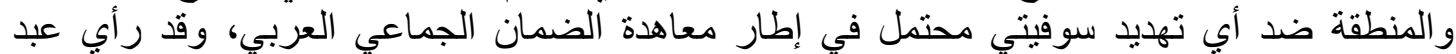

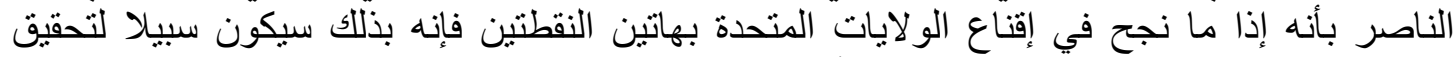

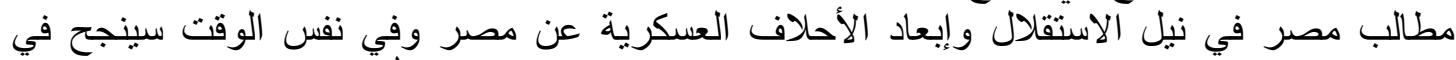

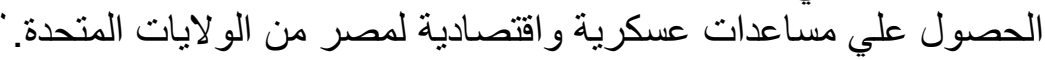

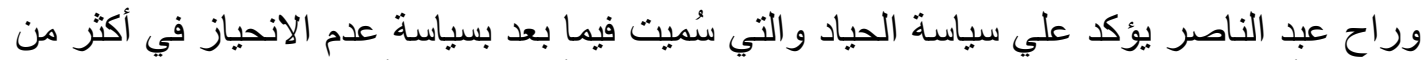

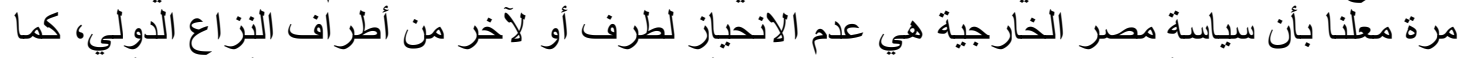

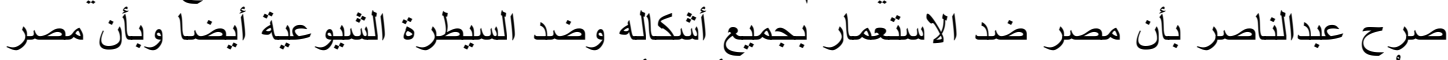

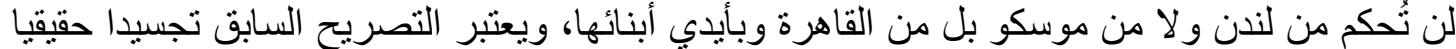

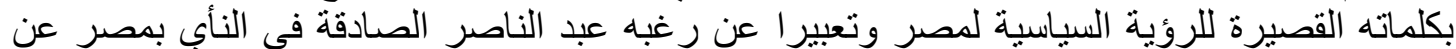

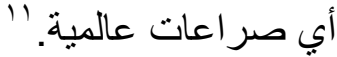

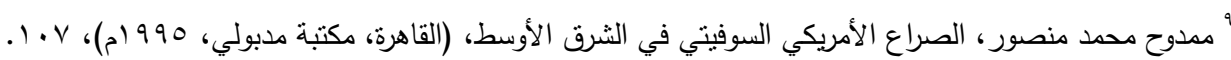

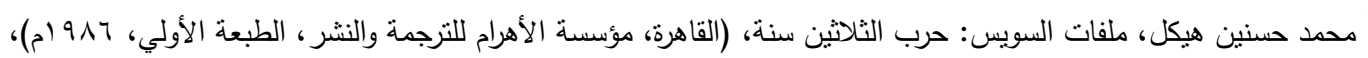


وبالر غم من حرص الولايات المتحدة منذ قيام الثورة في مصر إقامة صداقة قوية مع القيادة الجديدة

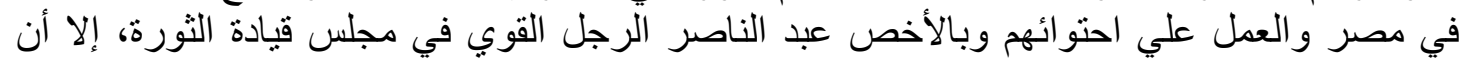

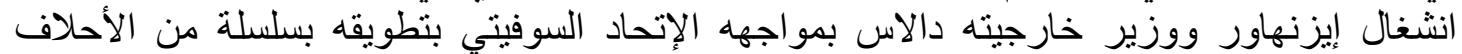

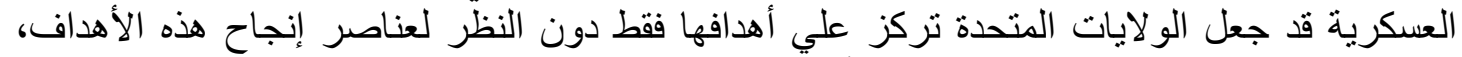

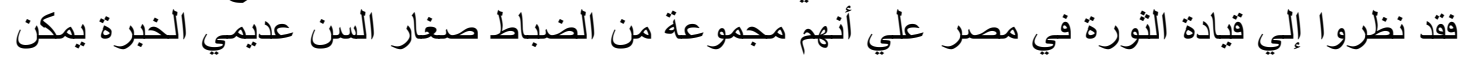

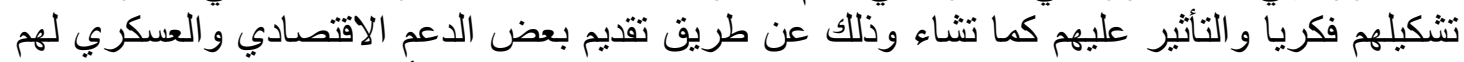

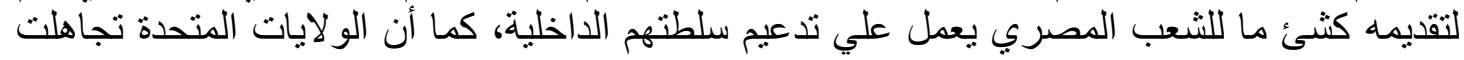

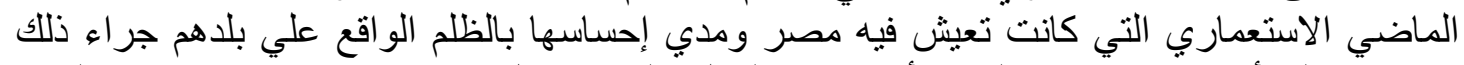

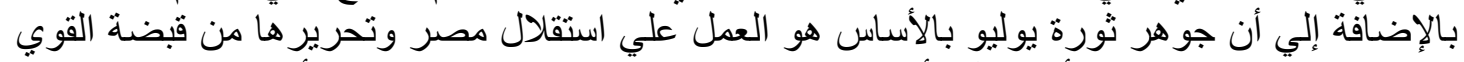

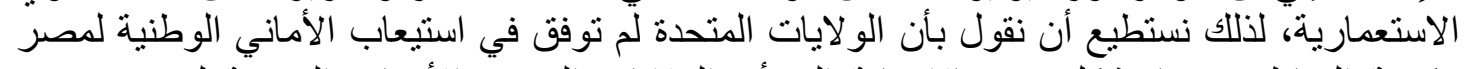

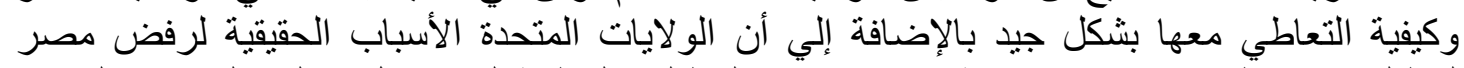

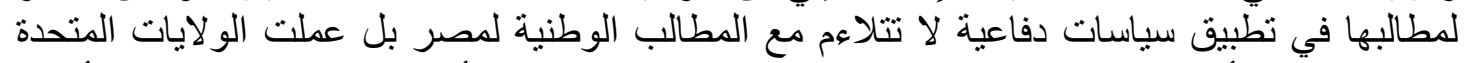

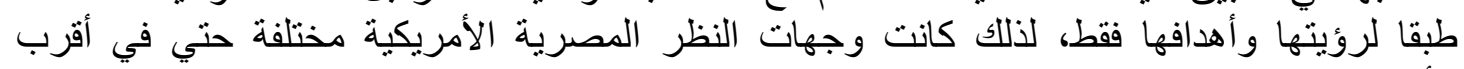

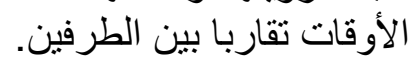

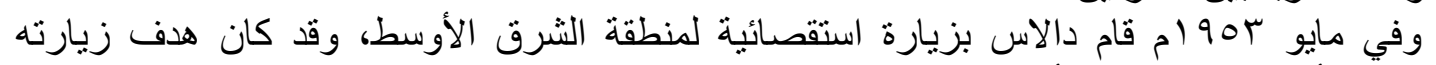

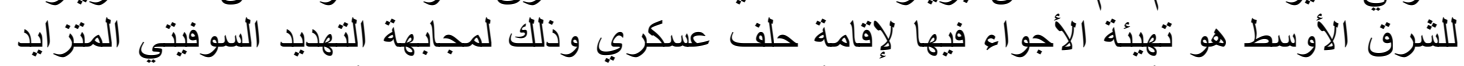

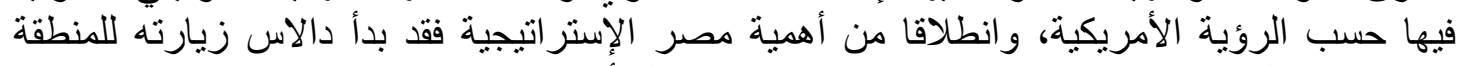

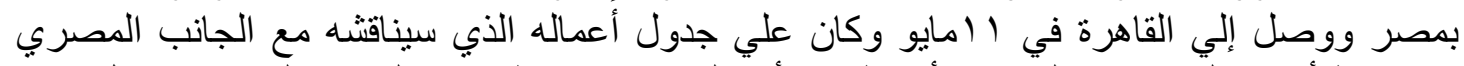

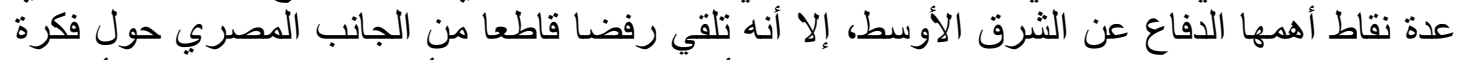

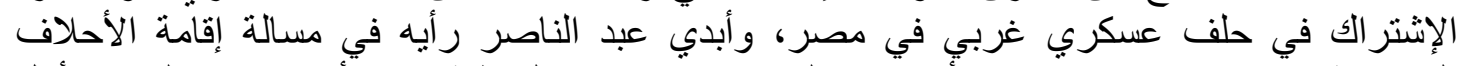

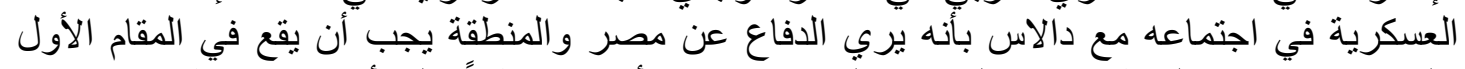

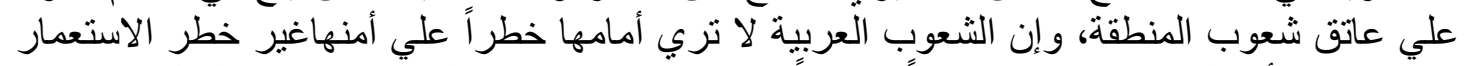

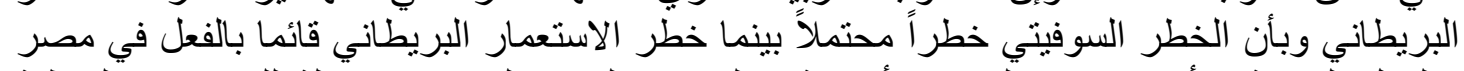

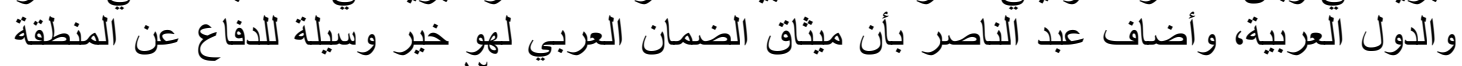

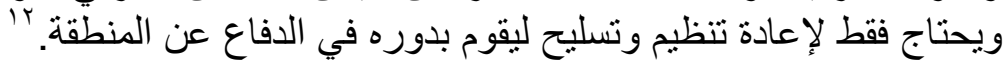

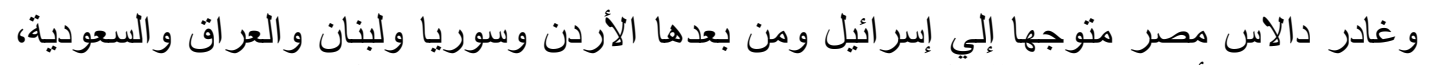

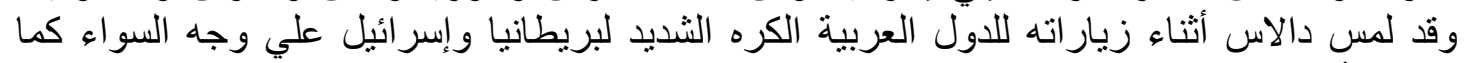

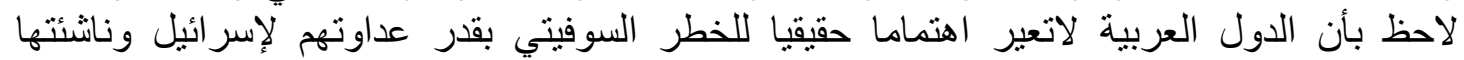

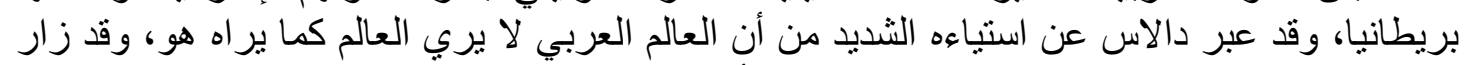

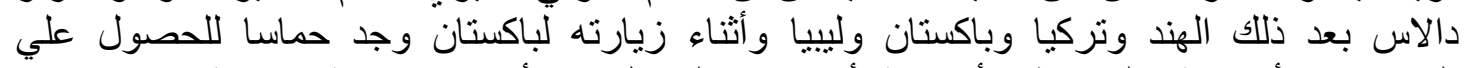

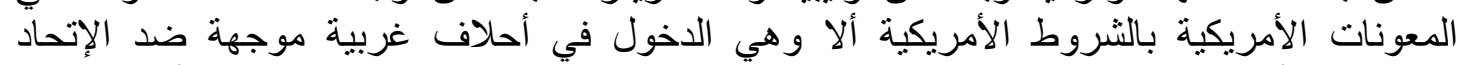

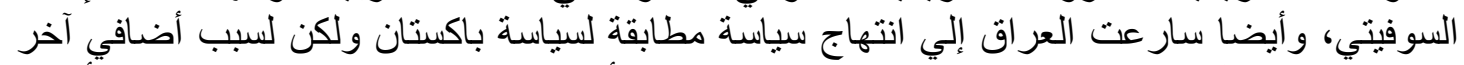

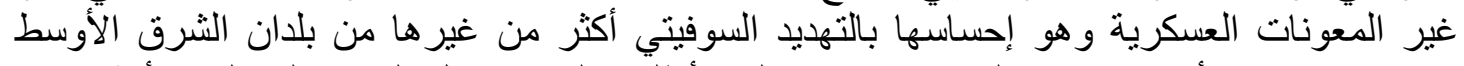

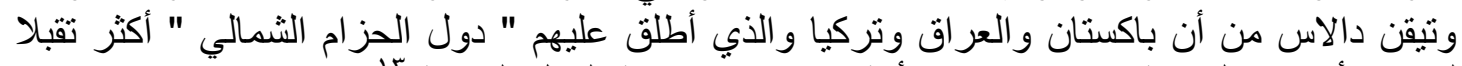

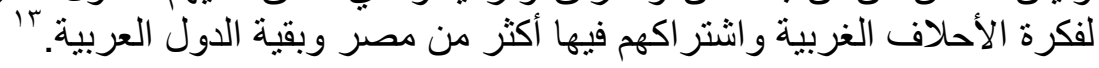

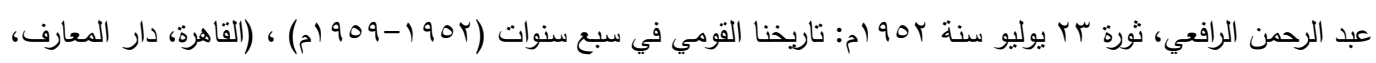

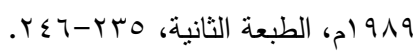

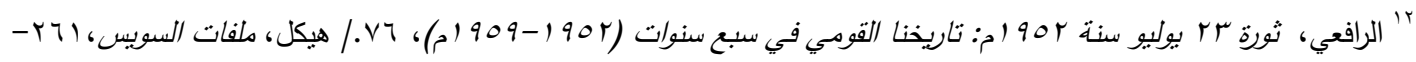

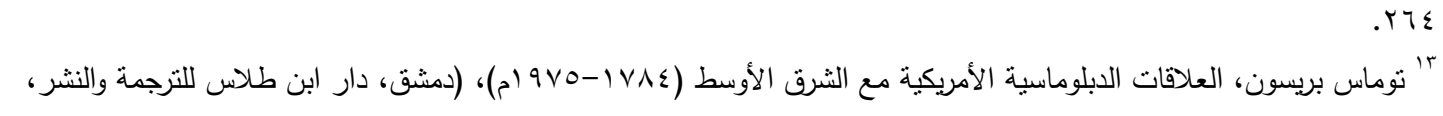
$.1 \leq 0$ ، (م) 1910 محمد عبد الوهاب سبد أحمد، العلاقات المصرية الأمريكية: من التقارب إلي التباعد (190r-190N ام)، (القاهرة، دار الثروق،

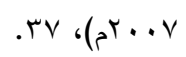




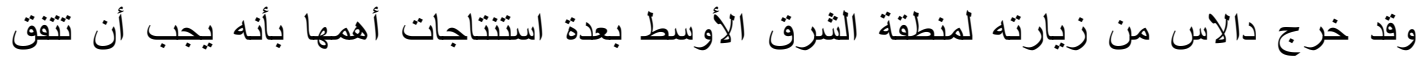

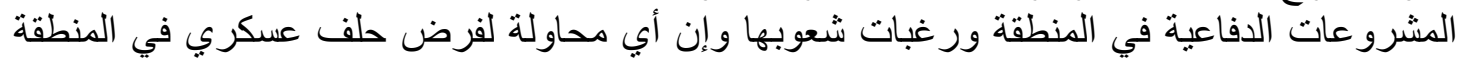

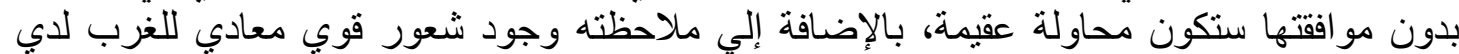

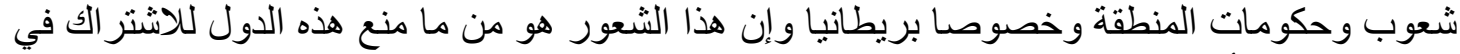

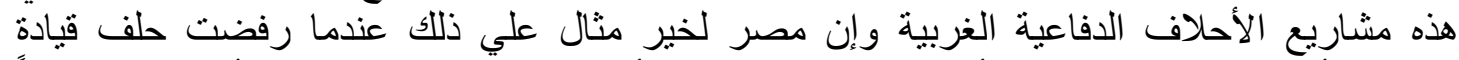

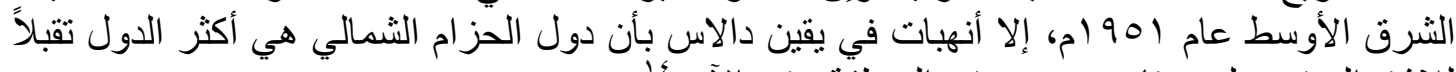

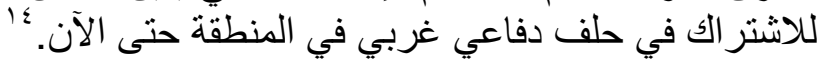

\section{r) نغير الإستر اتيحية الدفاعية الأمريكية نحو دول الحزام الثمالي بليلاً عن قاعدة السويس}

مع رفض مصر القاطع المشاركة في أي ترتيبات دفاعية بعيدا عن إطار اتفاقية الدفاع العربي

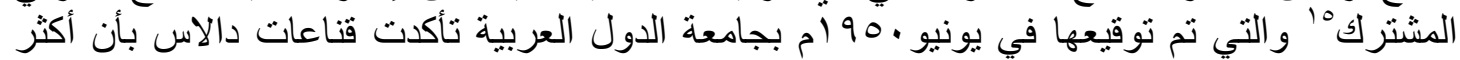

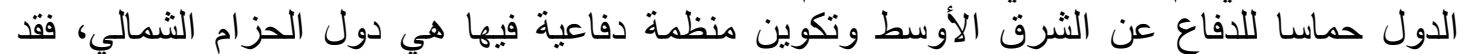

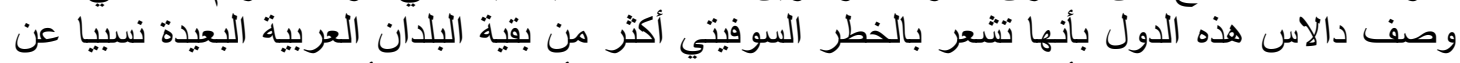

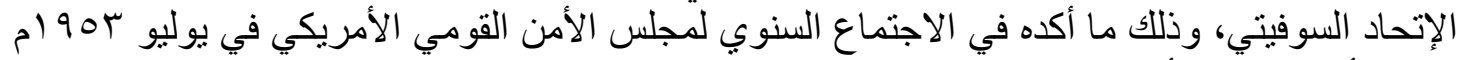

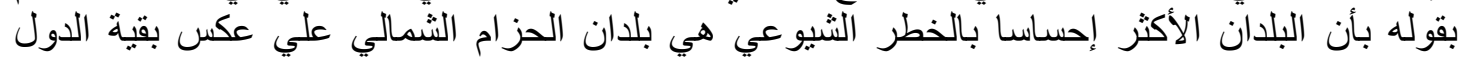

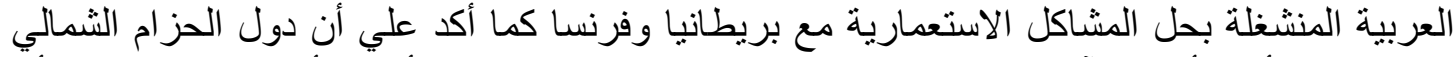

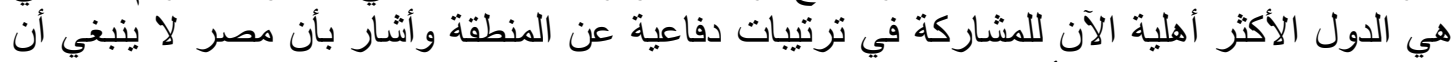

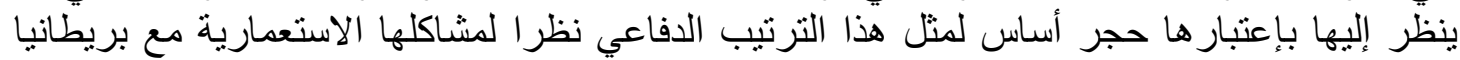

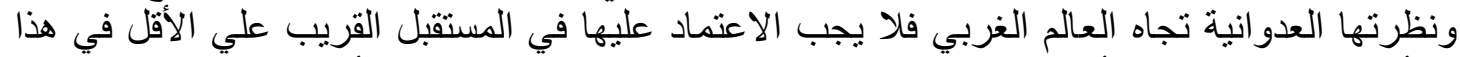

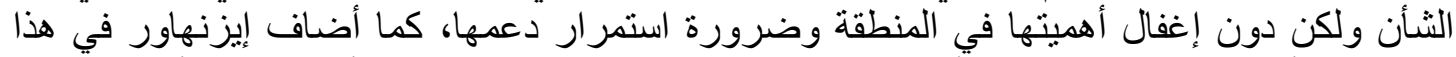

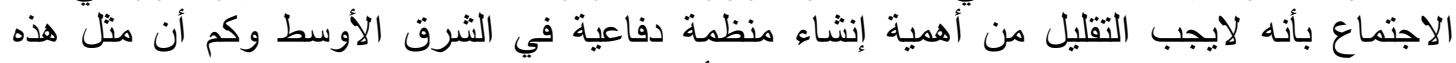

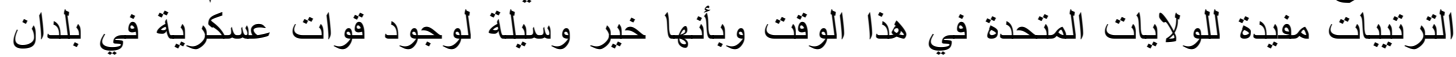

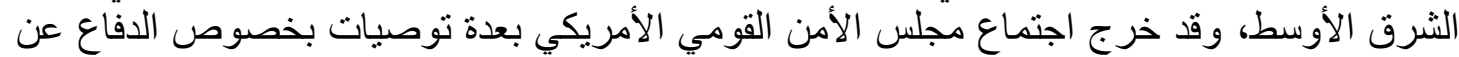

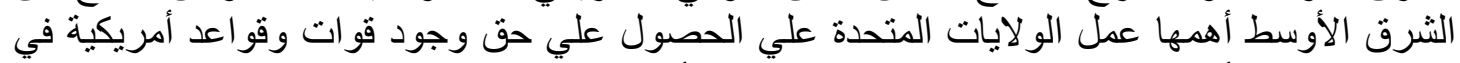

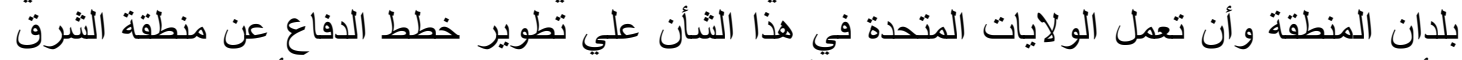

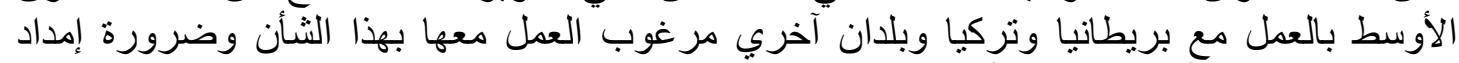

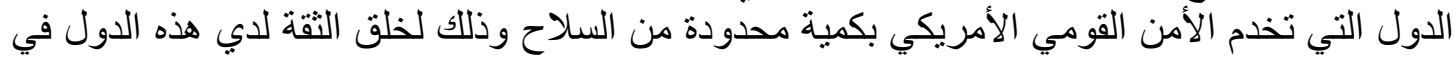

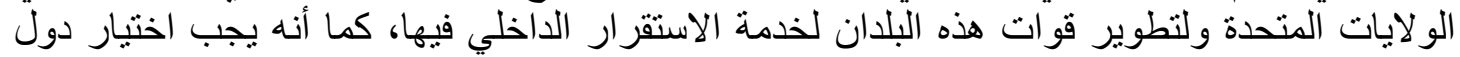

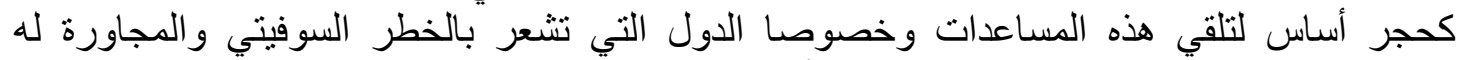

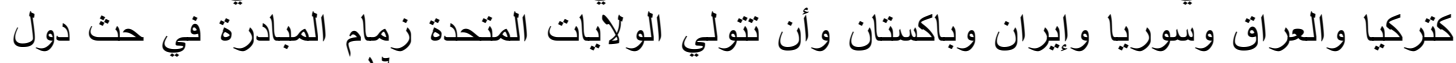

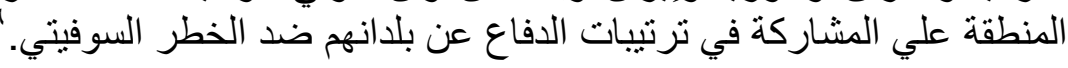

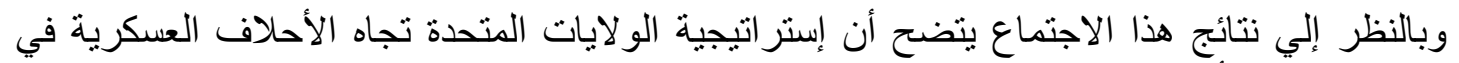

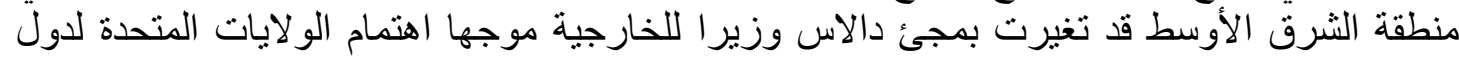

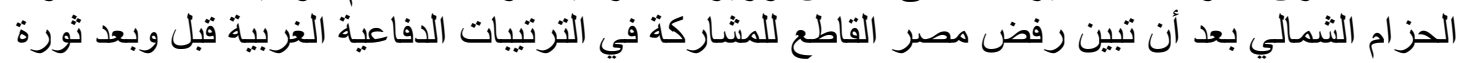
يوليو 90 (م) م.

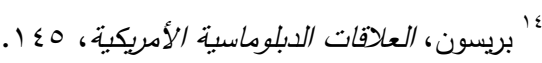

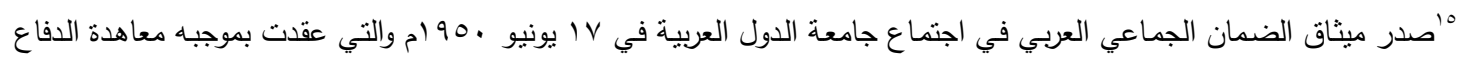

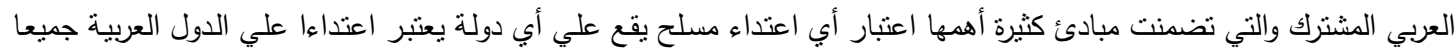
وكان أعضائها وقت توقيع الإتفاقية هم مصر والسعودية واليمن والعراق وسوريا ولبنان والأردن. www.lasportal.org

US National Security Council files, Statement of policy by the national Security Council, Washington, July 14, 1953, Top secret, archive NO. NSC 155/1. 
ونظرت مصر للتحول السياسي الأمريكي بشئ من عدم الارتياح خاصة عندما وافقت الولايات

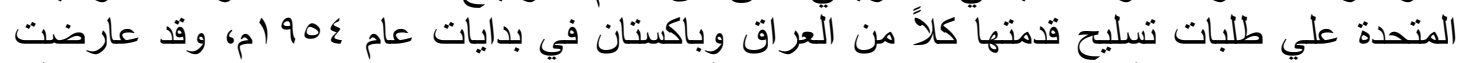

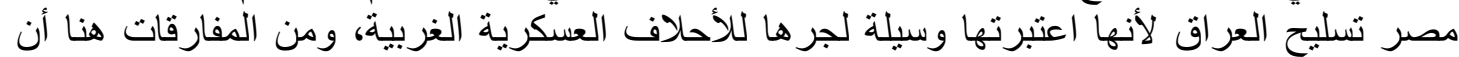

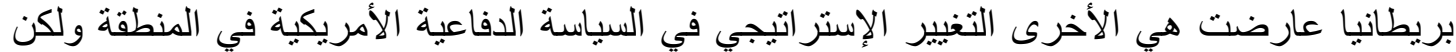

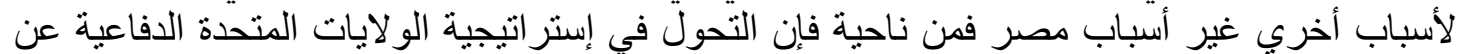

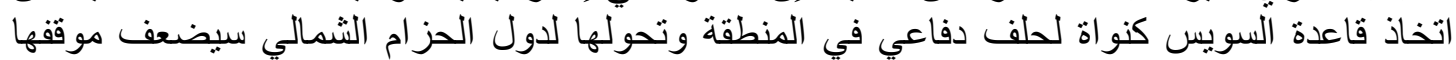

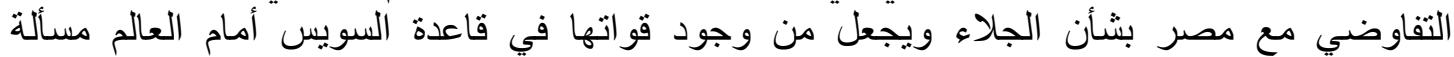
استعمارية من الدرجة الأولي وليست في إطار الخطط الدفاعية عن المنطقة، ومن ناحية أخري فقد

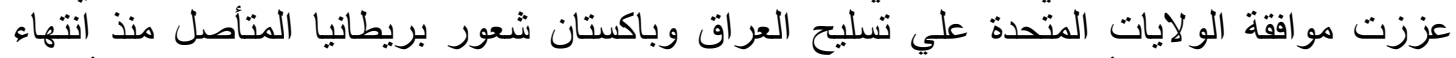

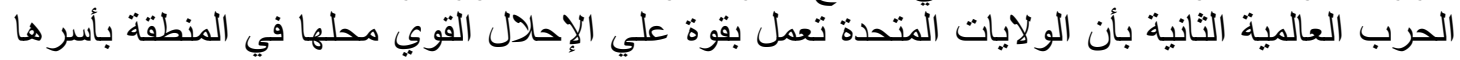

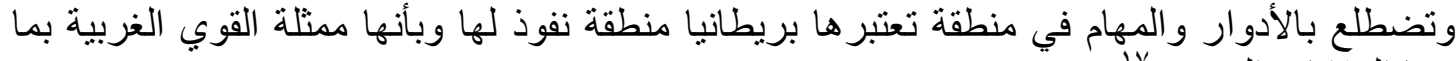

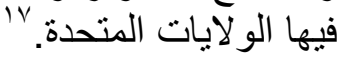

\section{؛ ) إنشاء حلف بغداد}

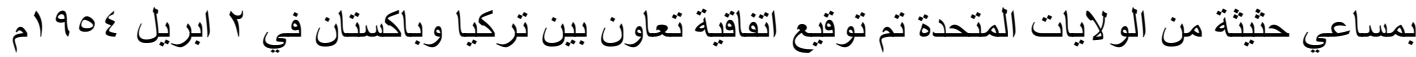

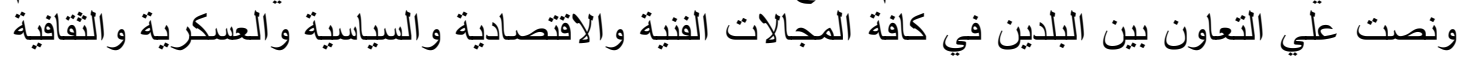

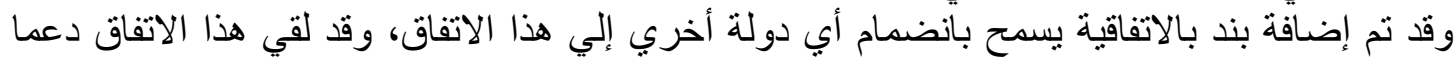

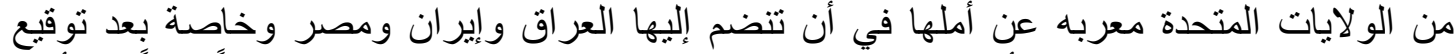

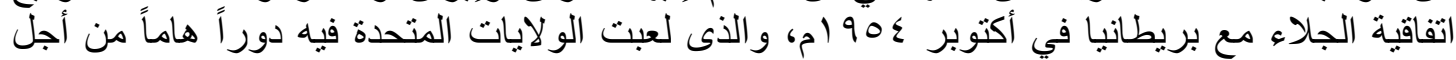

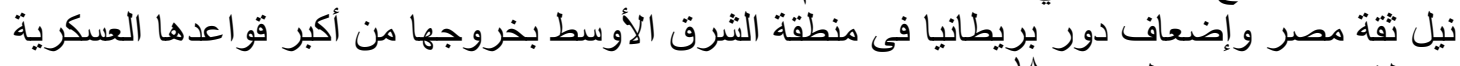

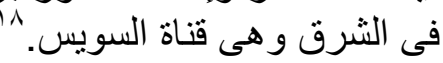

وفي مايو ـو 90 ام تم عقد مؤتمر ا دبلوماسيا بإسطنبول لرؤساء البعثات الأمريكية في الثرق الأوسط

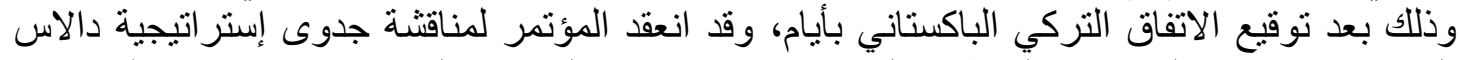

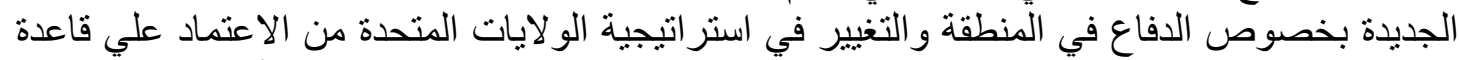

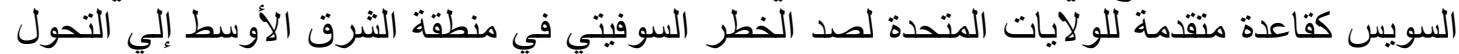

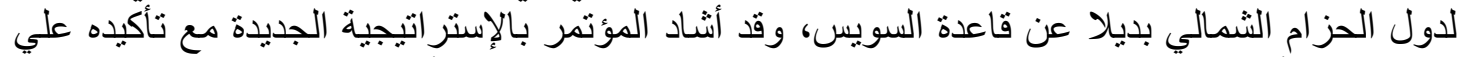

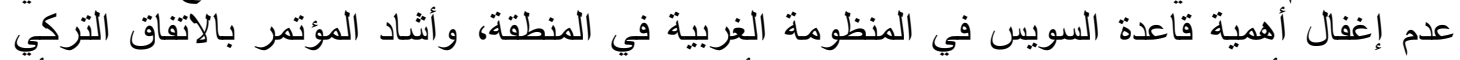

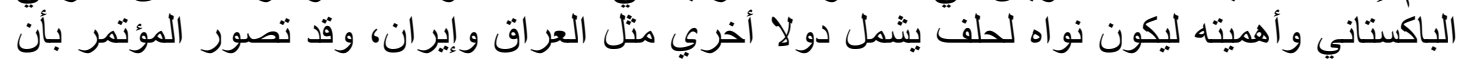

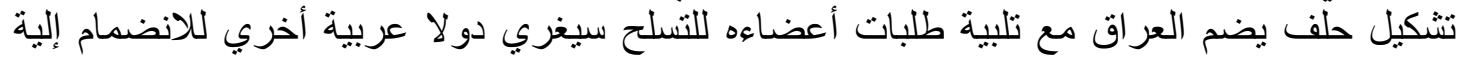

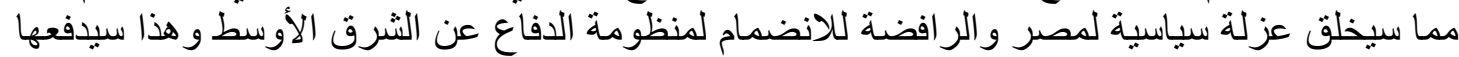

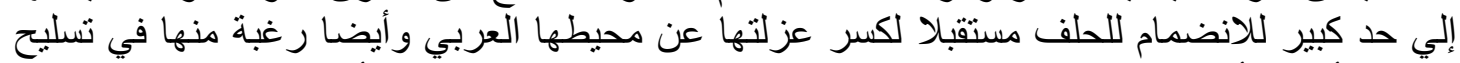

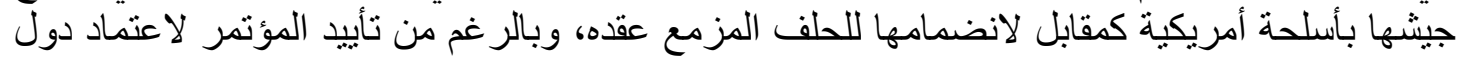

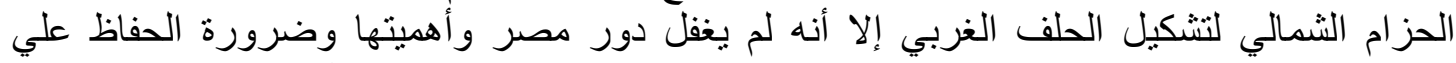

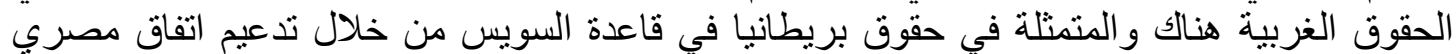
بريطاني يؤكد هذه الحقوق.

"جيفري أرونسون، واشنطن تخرج من الظل: السياسة الأمريكية نجاه مصر (7؟ 9 (1-907 ام)، ترجمة سامي الرزاز ، (القاهرة،

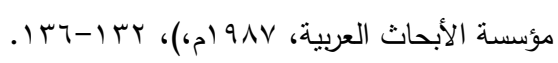

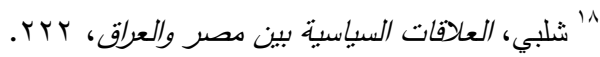




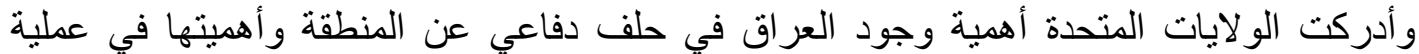

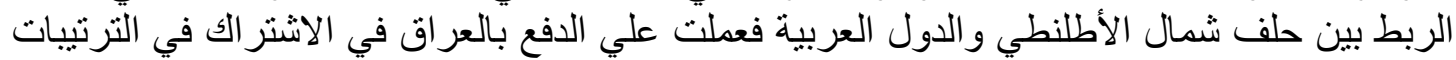

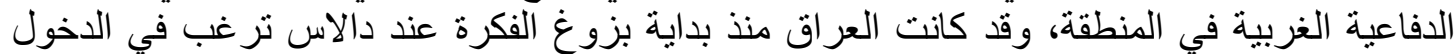

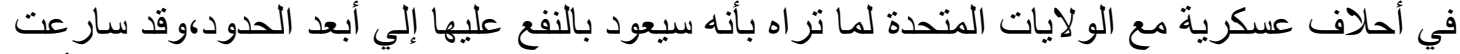

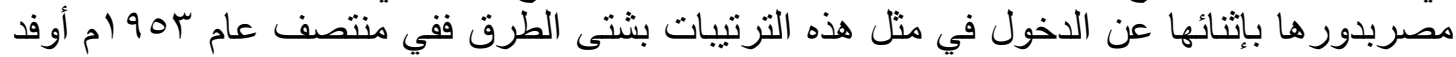

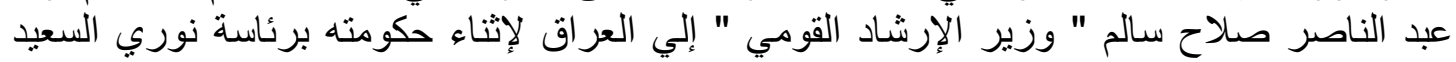

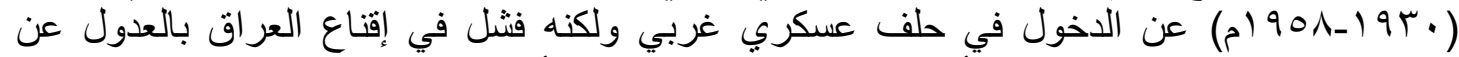

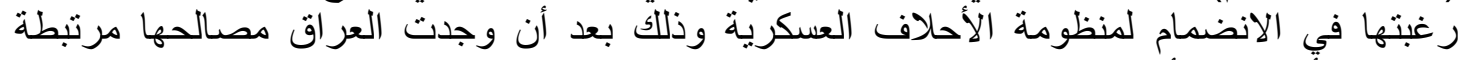

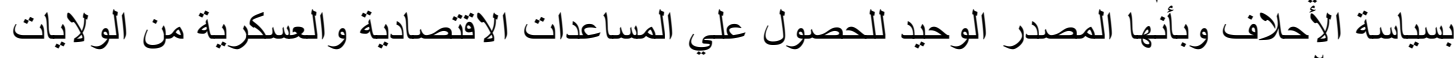

\section{๑) مقاومة مصر لحف بغداد}

بعد أن تبين نية العراف الأكيدة للاخول في منظومة الأحلاف الغربية قام عبد الناصر بالاعوة إلي إلي

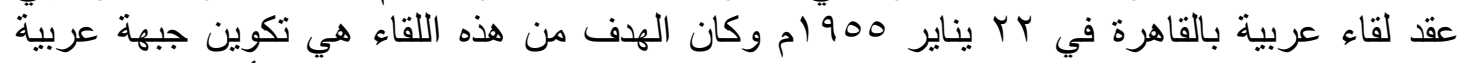

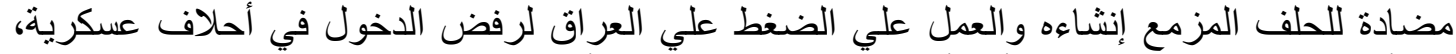

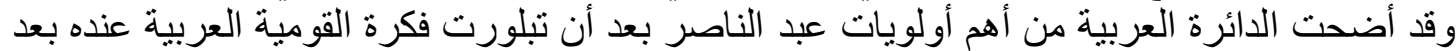

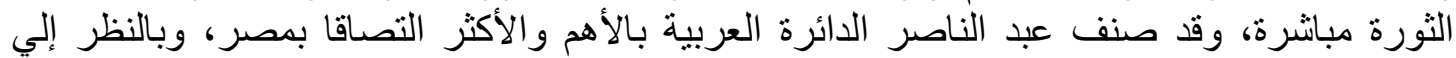

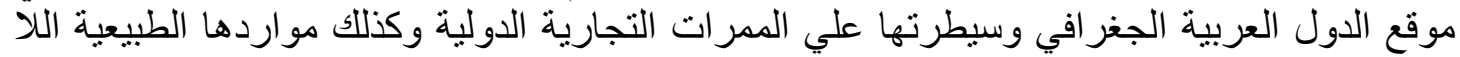

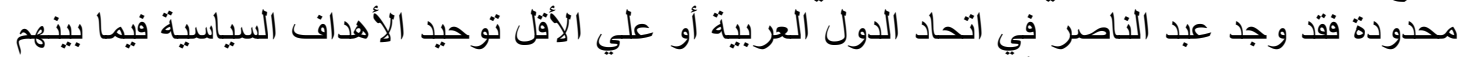

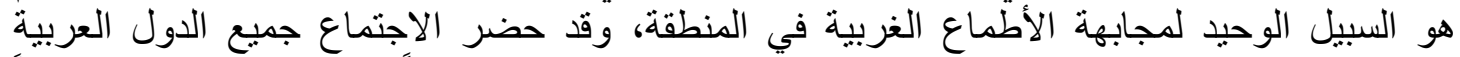

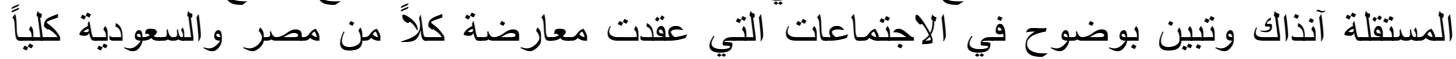

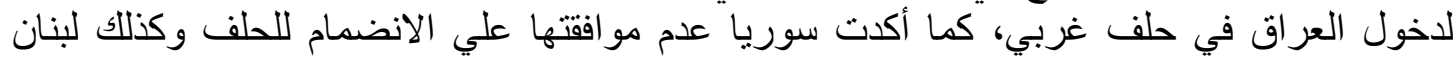

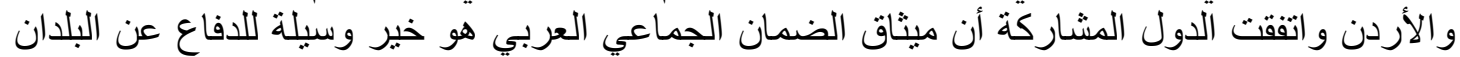

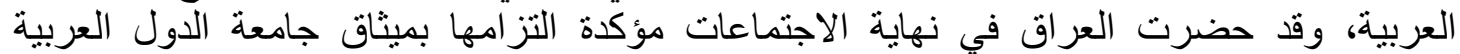

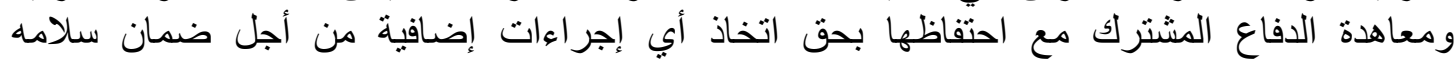

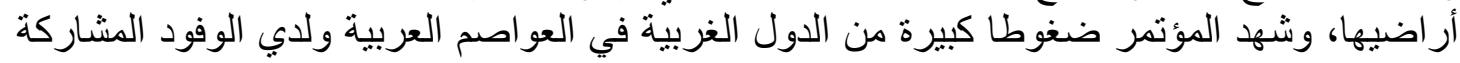

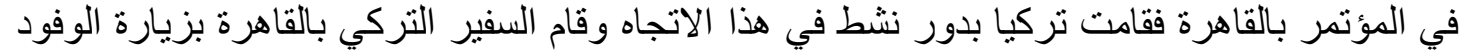

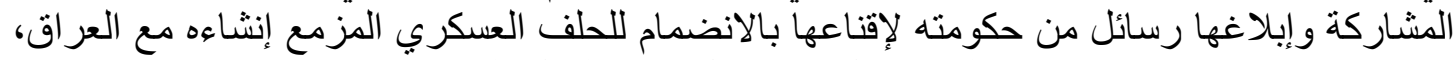

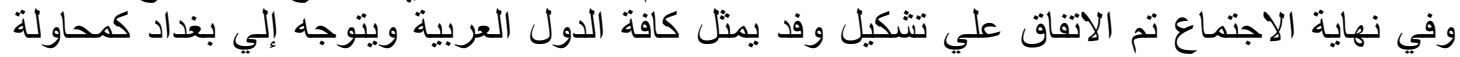

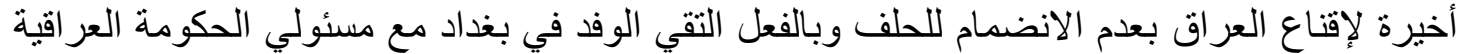

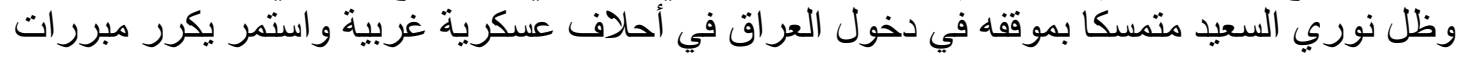

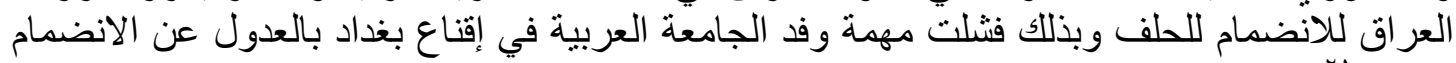

اللحلف

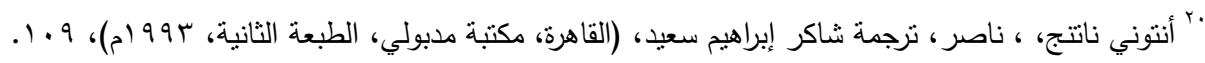

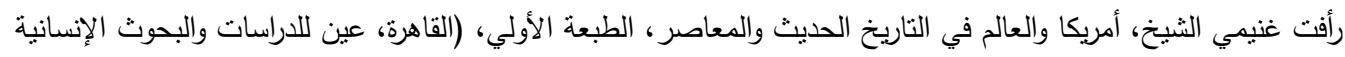

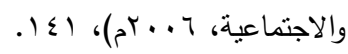

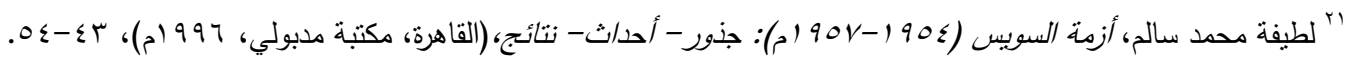

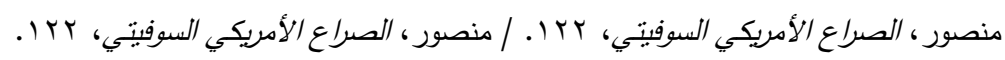

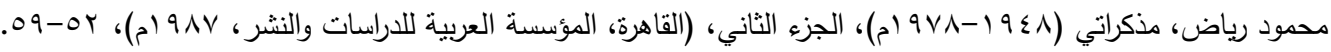




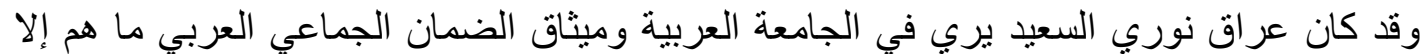

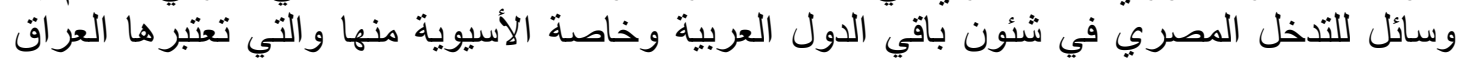

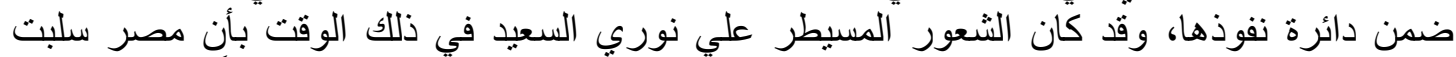
العراق دور ها لقيادة الدول العربية وقد أن الأوان لتلعب العران الق دور ها المستحق مستغلاً في ذلك حاجة الكان

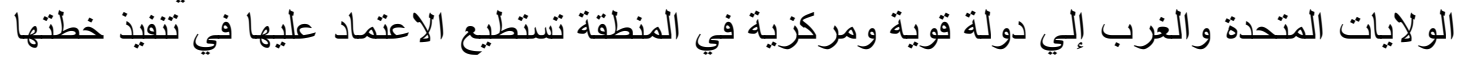

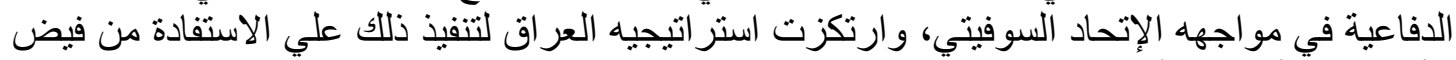

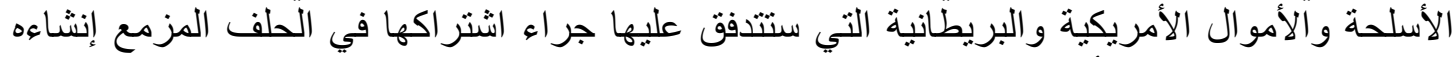

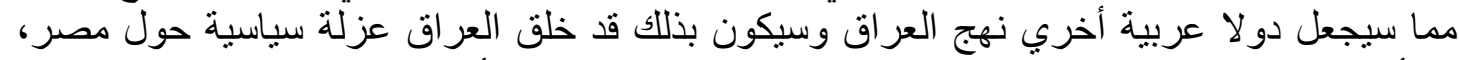

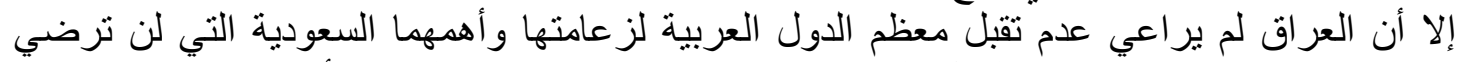

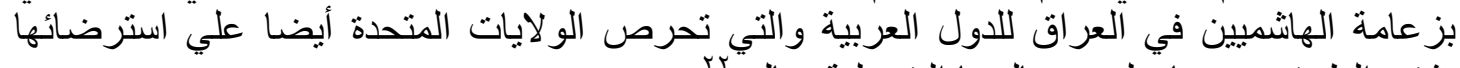

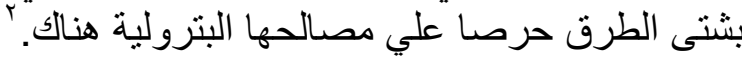

وقادت مصر حمله شرسة لمهاجمة العر اق وسياساته بشتى الطرق حتى يعيد التفكير في انضماهـ الإنها

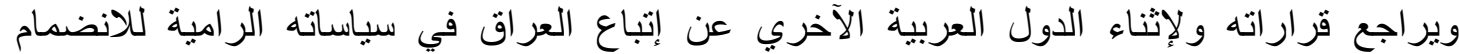

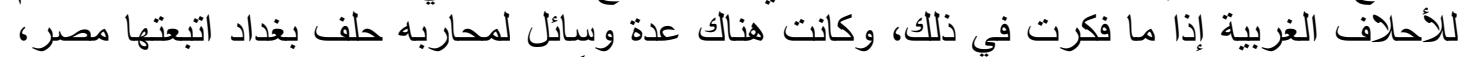

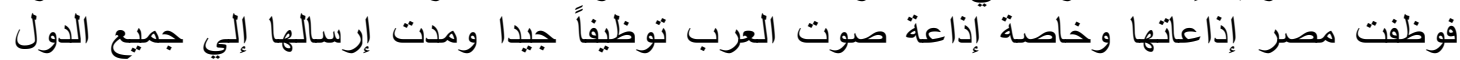

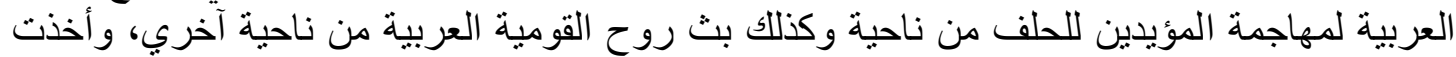

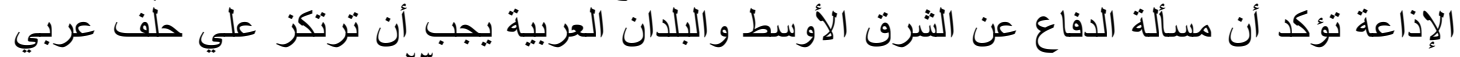

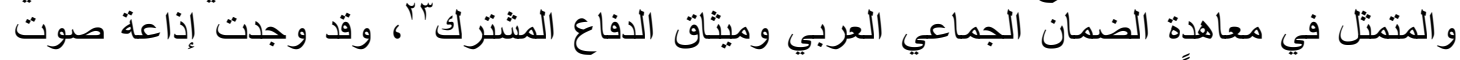

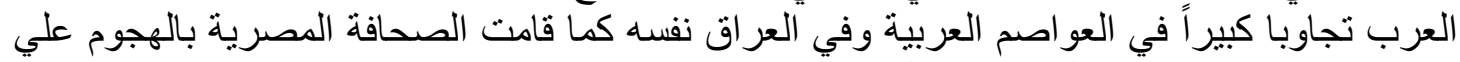

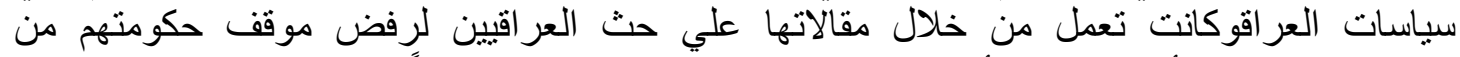

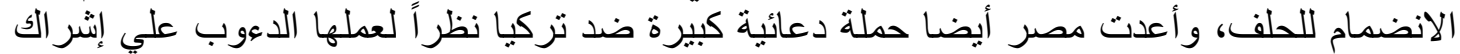

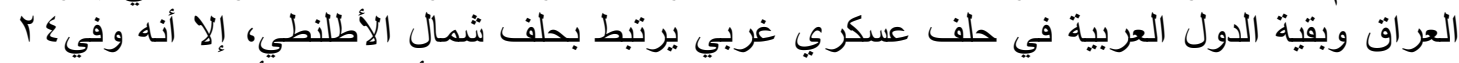

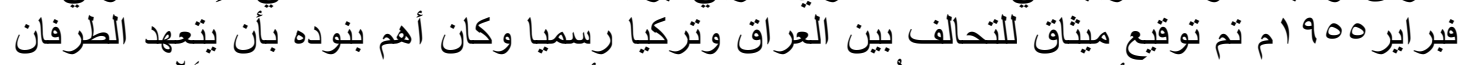

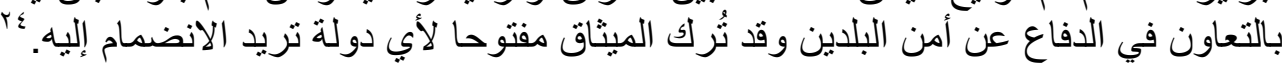

وقد مثل عقد الميثاق العر اقي التركي تهديدا كبير المصر فقد كانت مصر تتخوف خاصن خاصة من البند

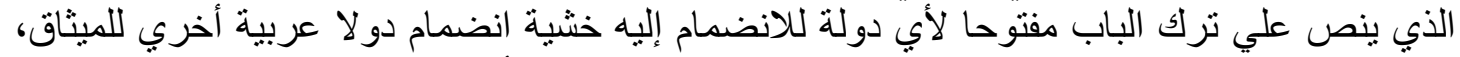

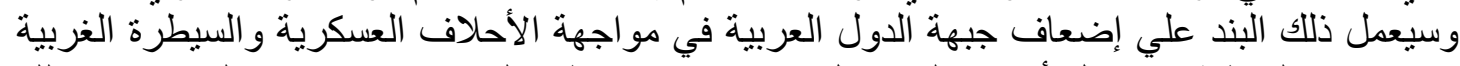

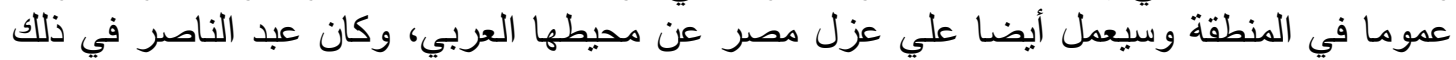

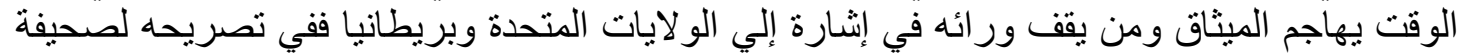

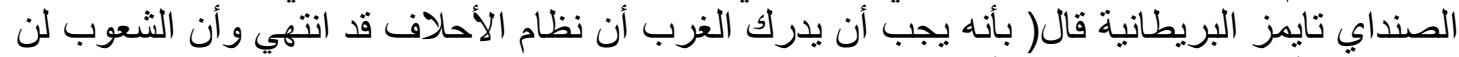

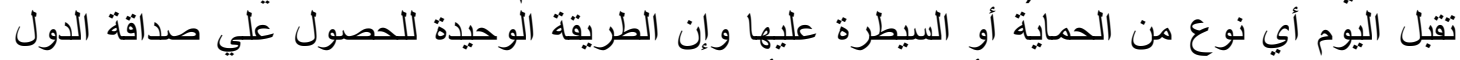

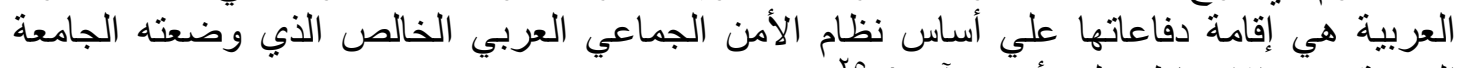
العربية بدون الارتباط بحلف أجنبي آخر ).

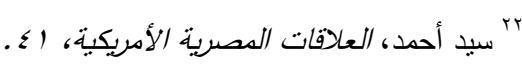

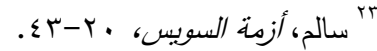

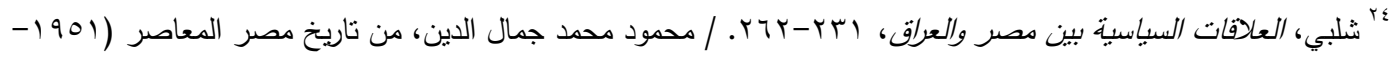

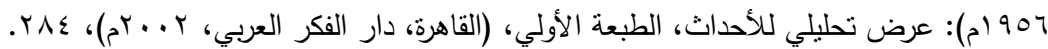

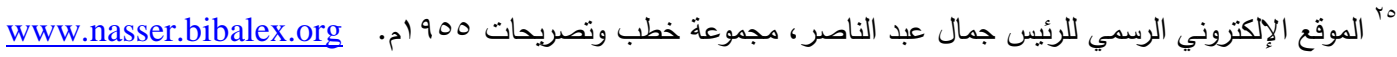


ورغم كل الجهود و النداءات المصرية المناوئة للميثاق العر اقي التركي فقد انضمت بريطانيا رسميا

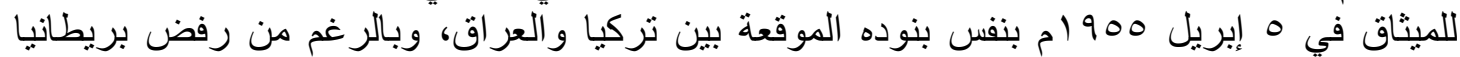

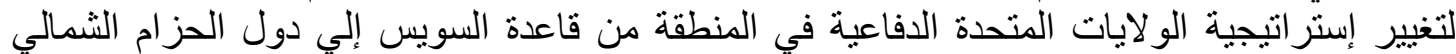

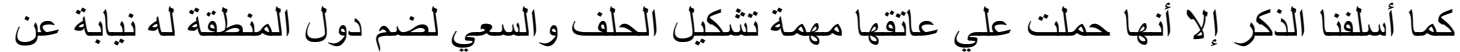

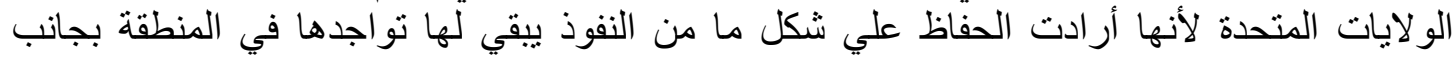

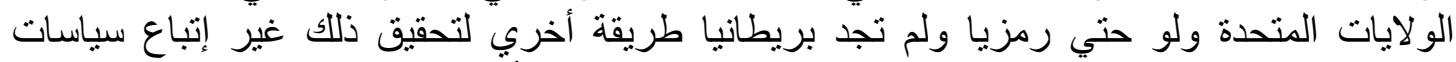

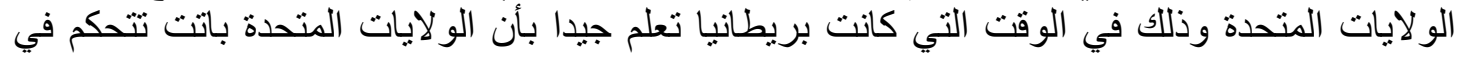

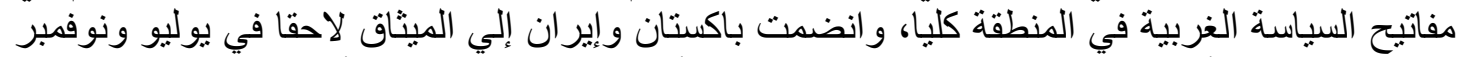

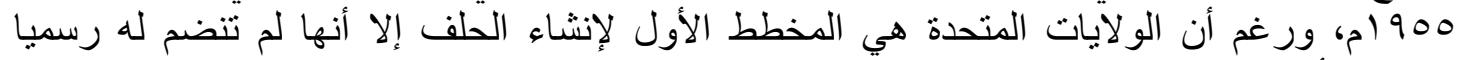

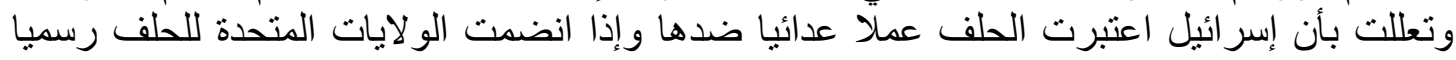

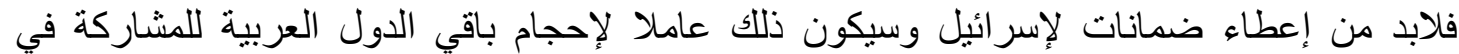

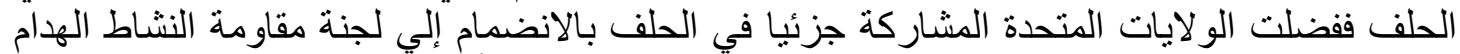

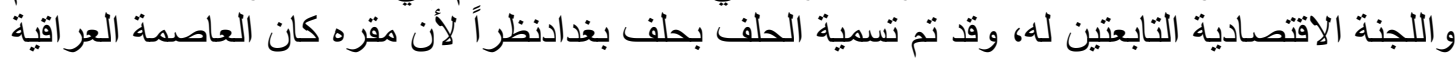

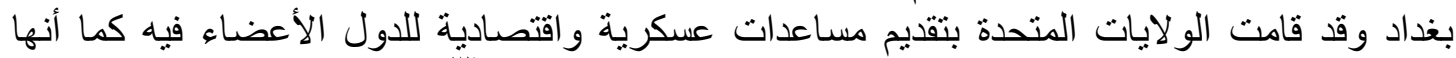

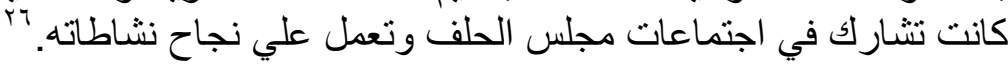

وقد احتوي حلف بغداد علي عدة لجان تتفيذية وتتمثل في:-

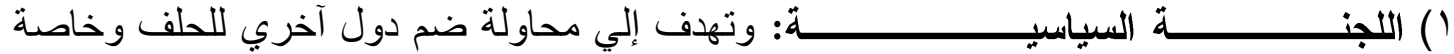

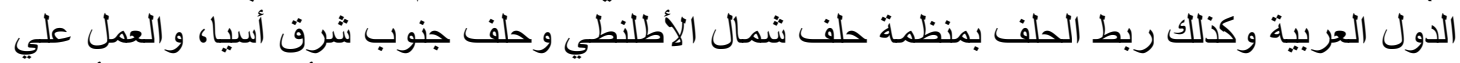
تطويق الإتحاد السوفيتي، بالإضافة للعمل علي توحيد السياسة الخارجية للدول الأعضاء إزاء إكاء الأحداث

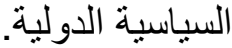

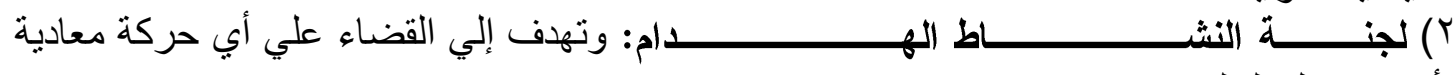

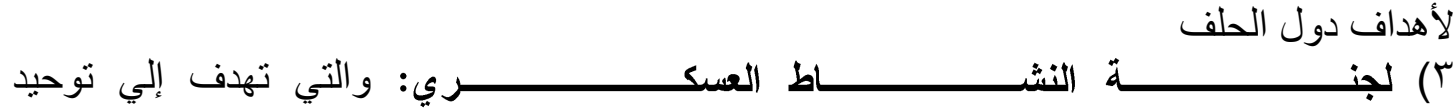
الجهود العسكرية وتتسيق الخطط الدفاعية لدول الحلف.

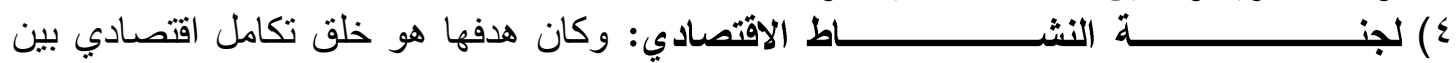
الدول الأعضاء وزيادة التبادل التجاري بينهم.

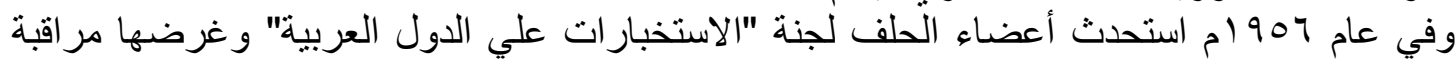
الدول العربية المناوئة لحلف بغداد وخاصة مصر وسوريا و السعودية.

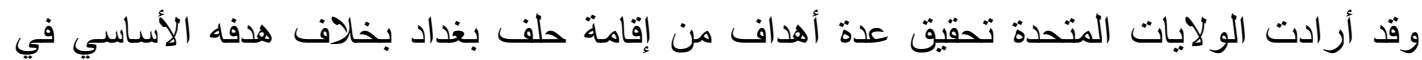

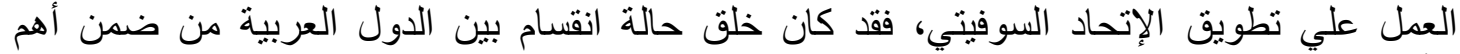

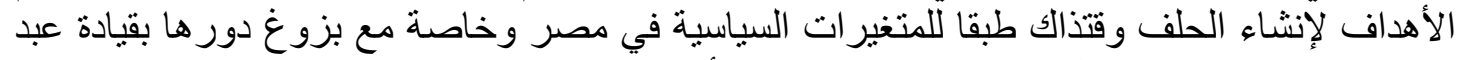

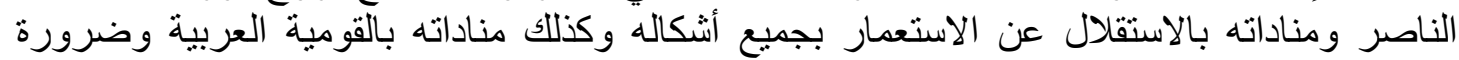

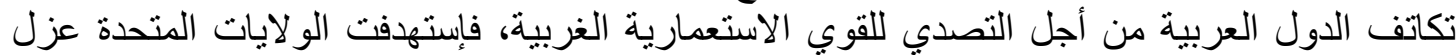

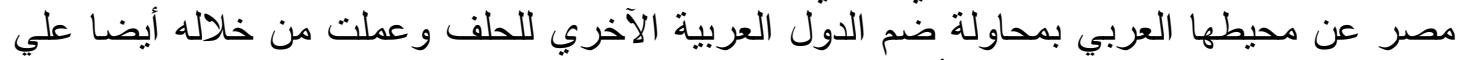

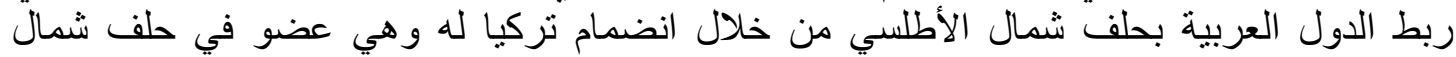

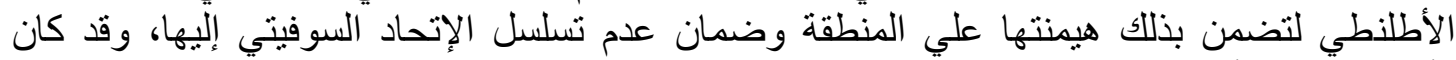

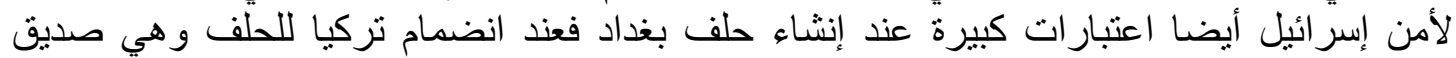

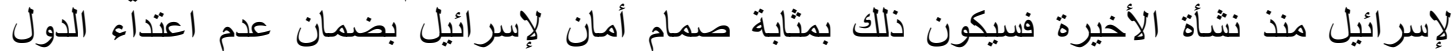

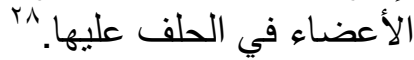

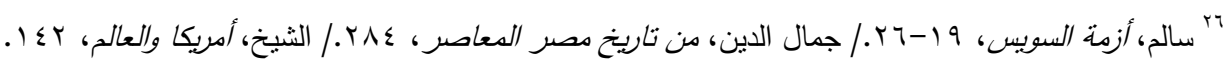

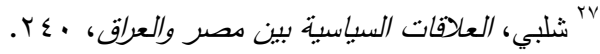

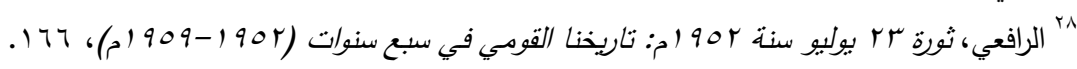

$$
\begin{aligned}
& -\Lambda \cdot-
\end{aligned}
$$


وقامت مصر بالتصدي لمحاولة ضم الأردن لحلف بغداد، فقد حاولت بريطانيا تعديل الاتفاقية الثنائية

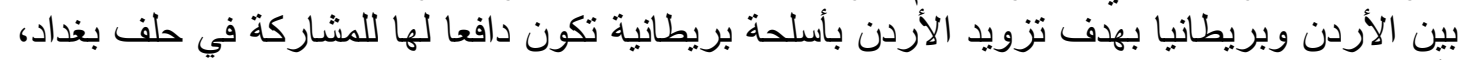

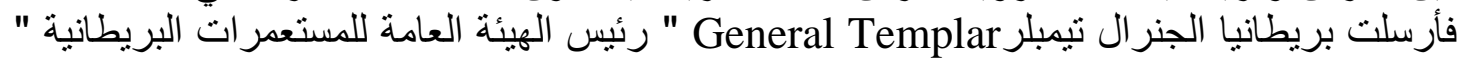

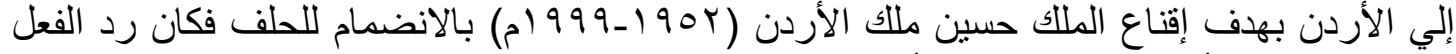

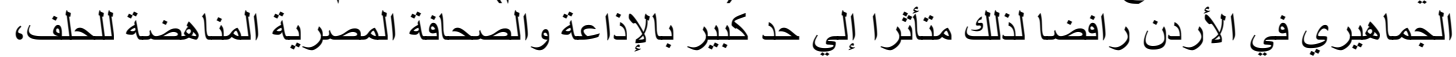

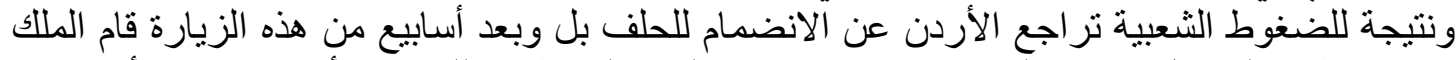

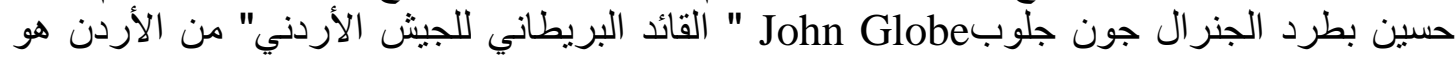

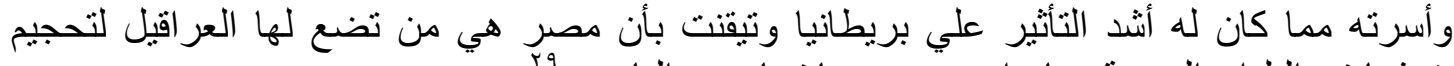

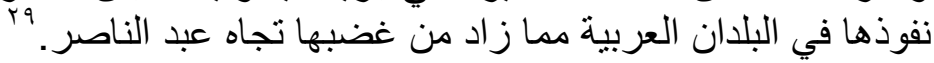

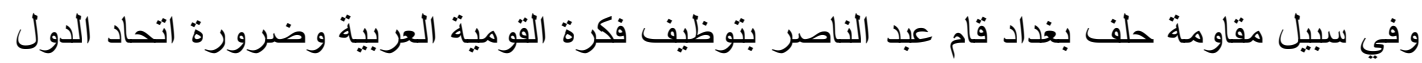

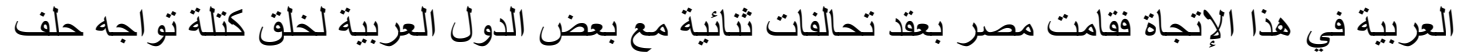

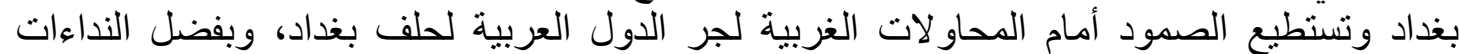

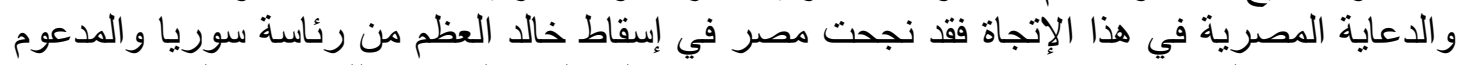

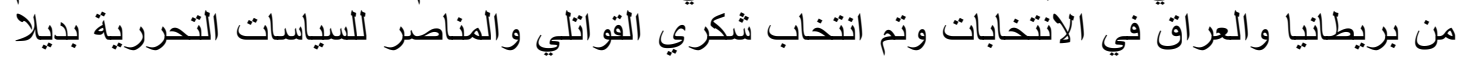

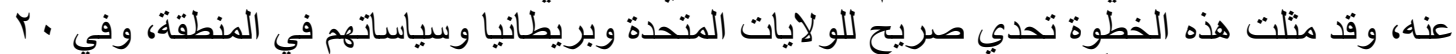

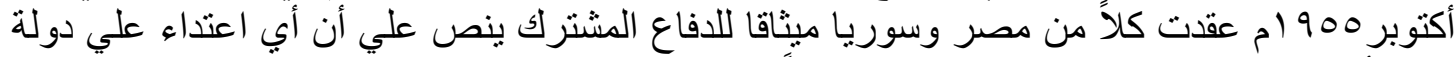

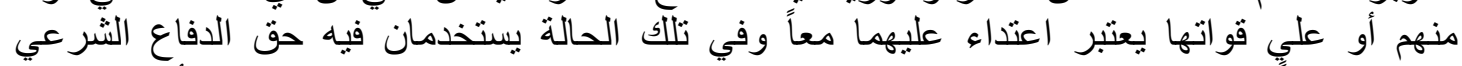

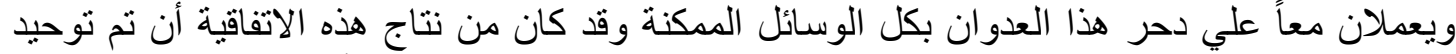

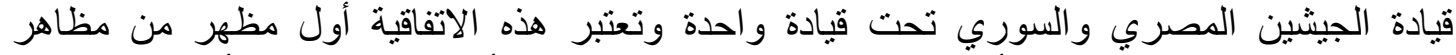

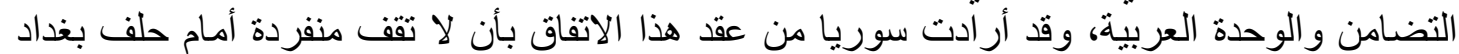

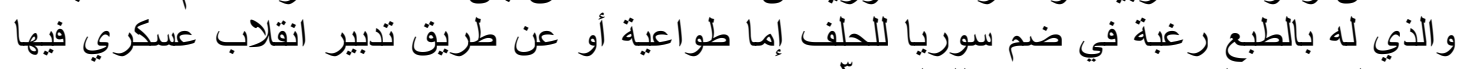

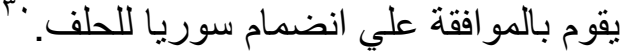

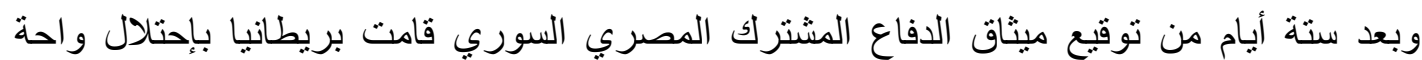

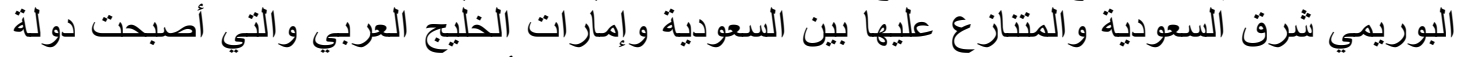

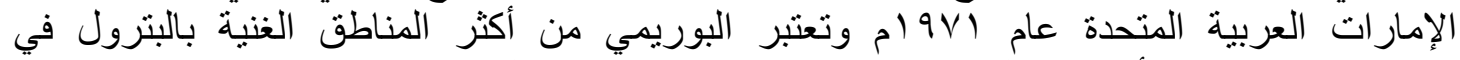

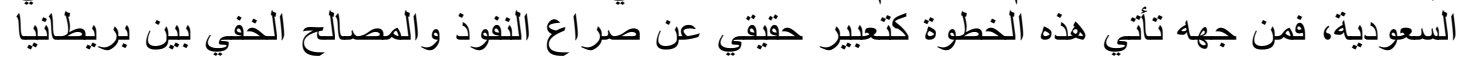

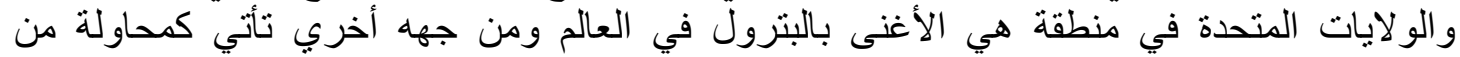

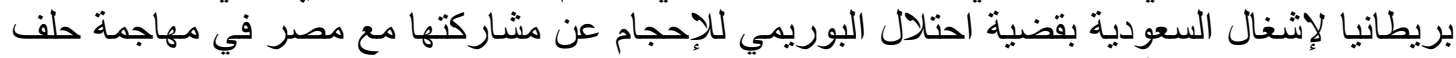

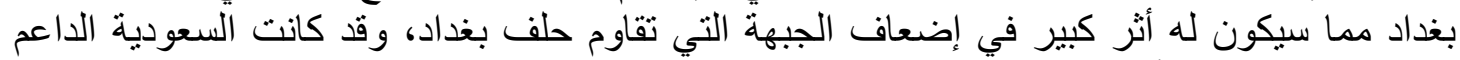

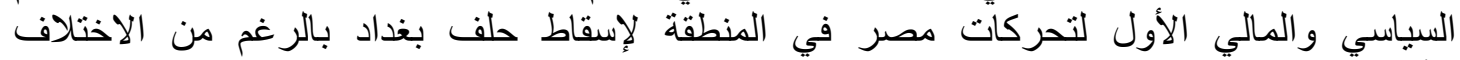

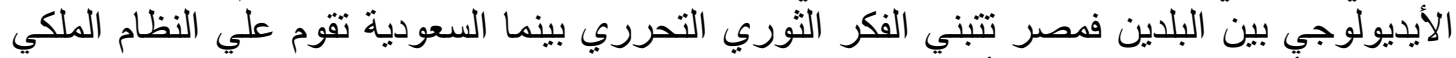

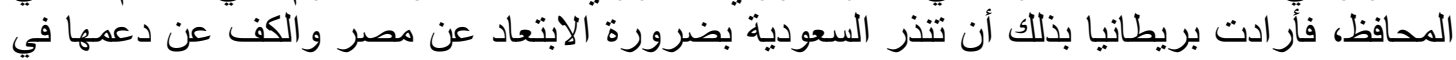

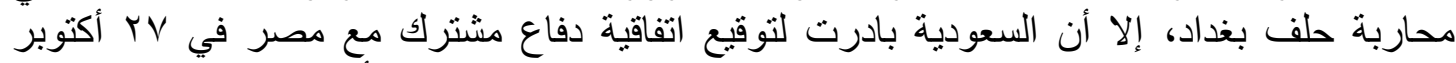

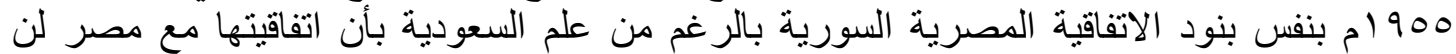

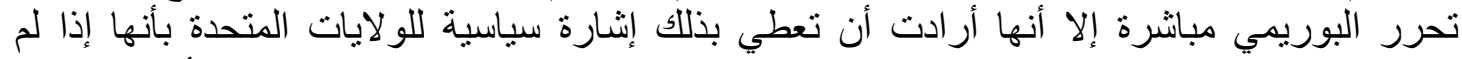

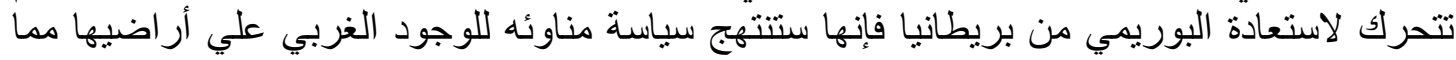

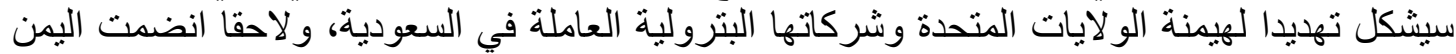

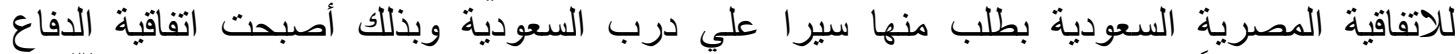

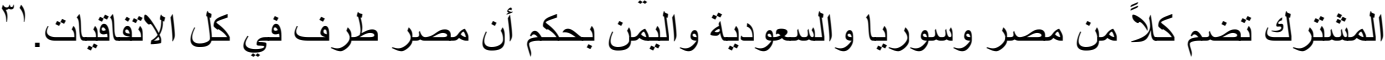

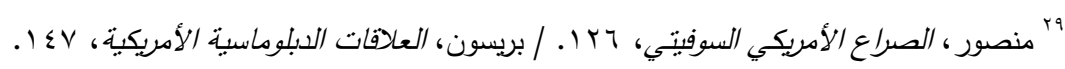

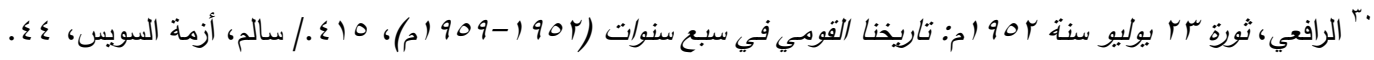

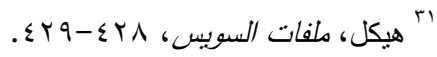


وبذلك فقد نجحت مصر في إثناء الدول العربية الفاعلة عن الدخول في حلف بغداد إلي حد كبير بل كبل بلدي

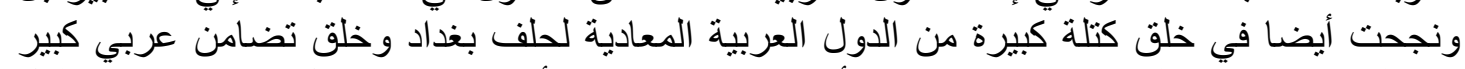

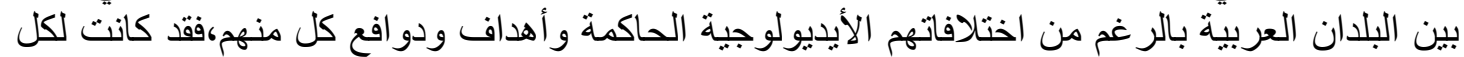

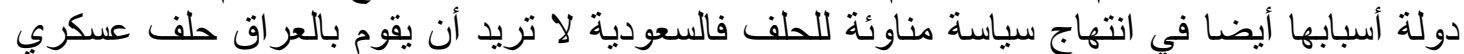

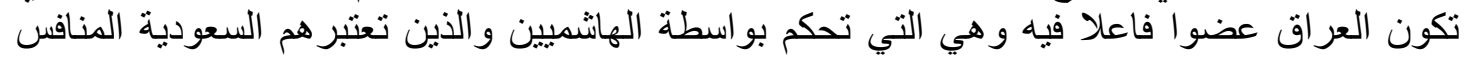

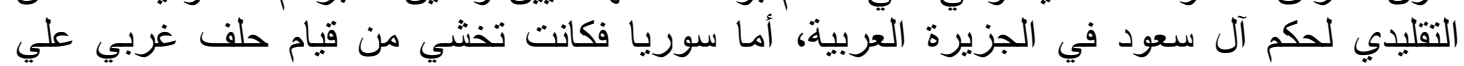

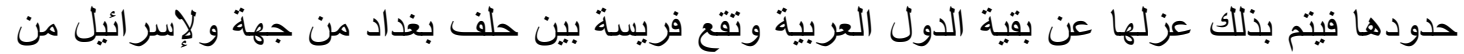

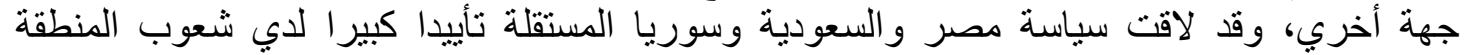

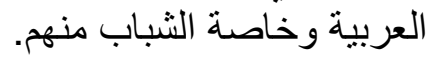

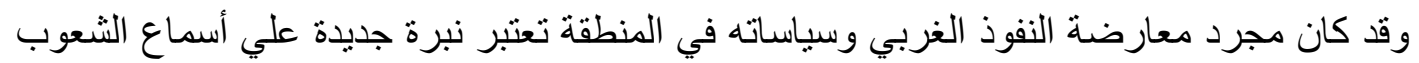

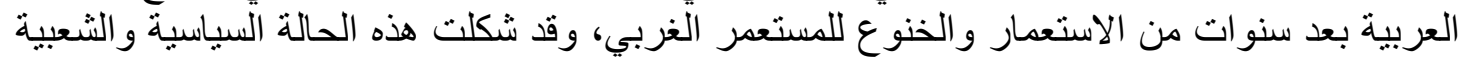

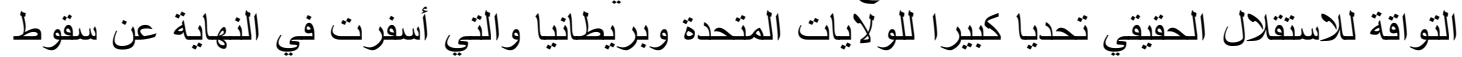

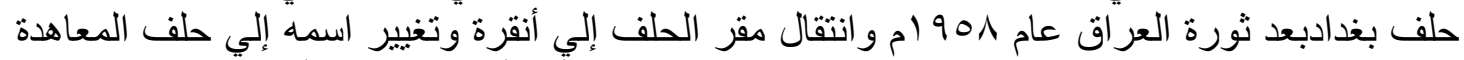

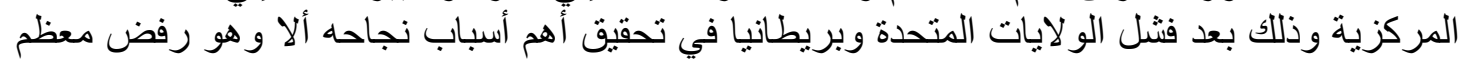

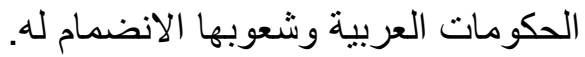

الخاتمة

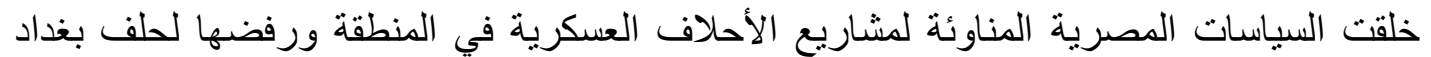

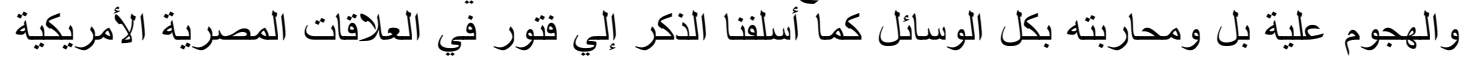

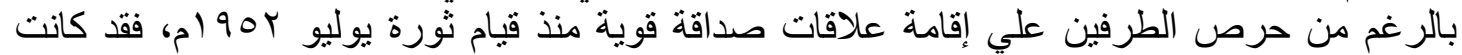

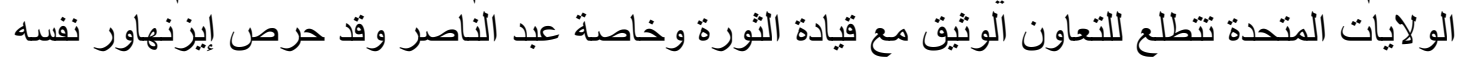

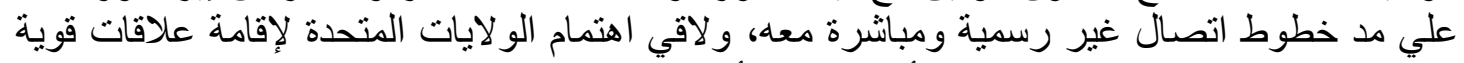

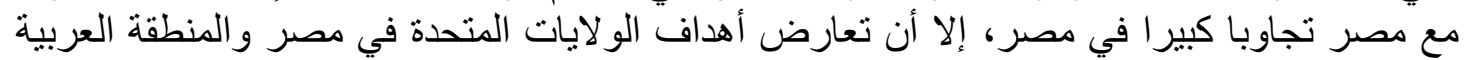

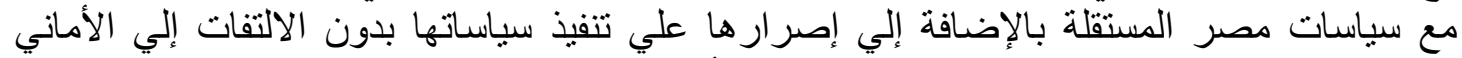

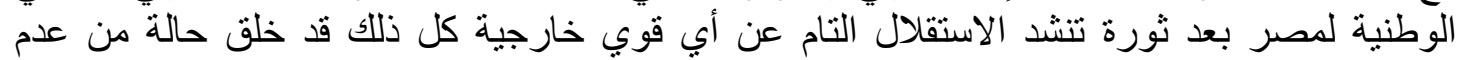

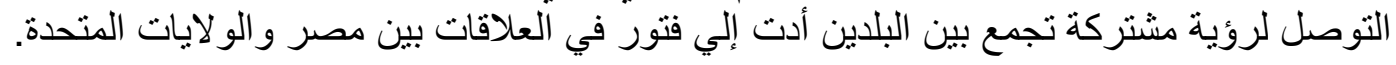

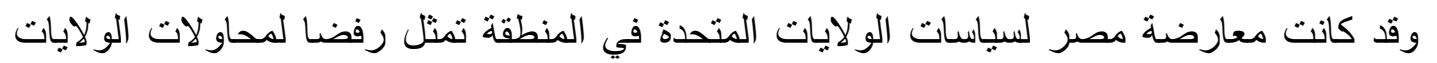

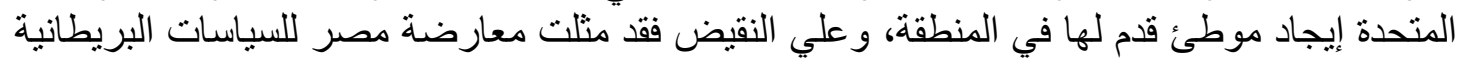

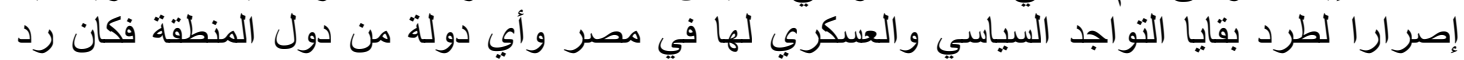

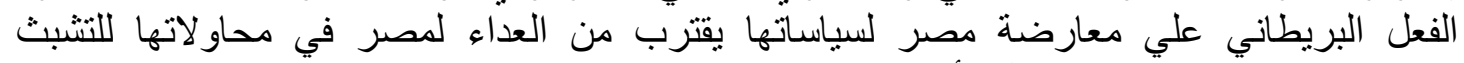

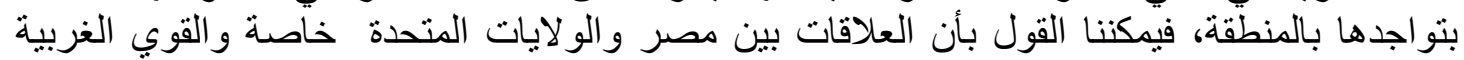

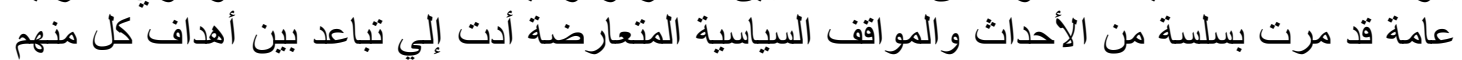

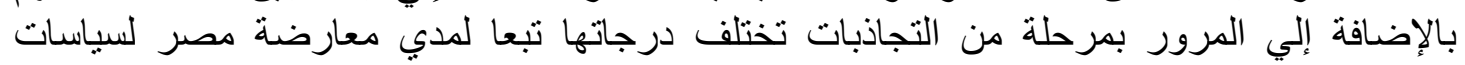
الولايات المتحدة والقوي الغربية في المنطقة العربية. 


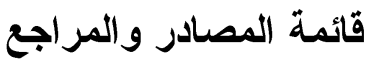

مأرسكين تثايلدرز، ترجمه محمد عبد اله الثققي، ب.ت، حول العالم العربي، القاهرة، الدار القومية

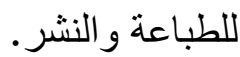

• • أنتوني ناتتج، ترجمة شاكر إبرا هيم سعيد، بو9 (9) ام، الطبعة الثانية، ناصر، القاهرة، مكتبة مدبولي.

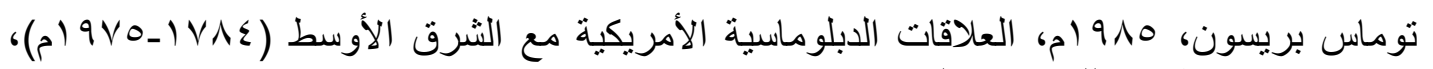
دمثق،دار ابن طلاس للترجمة و النشر.

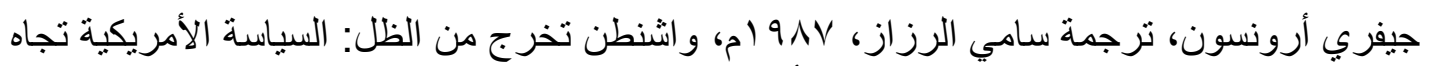

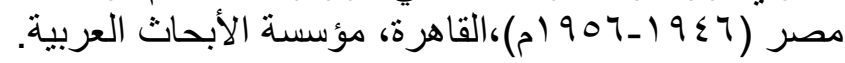

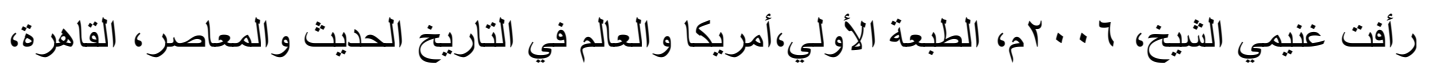
عين للار اسات و البحوث الإنسانية والاجتماعية.

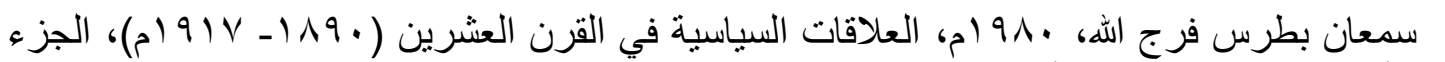
الأول، القاهرة، الدكتبة الأنجلو مصرية.

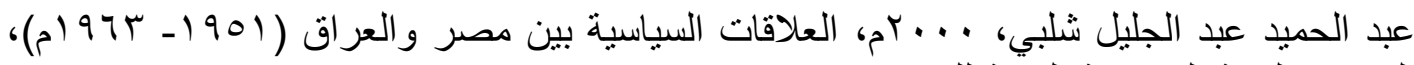
القاهرة، الهيئة المصرية العآمة للكتاب. • عبد الخالق عبد الله، العالم الدعاصر والصراعات الدولية، 919 ام، سلسلة عالم المعرفة، الكويت،

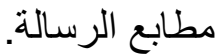

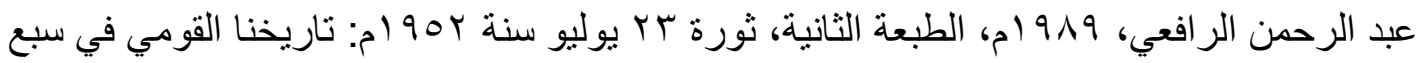

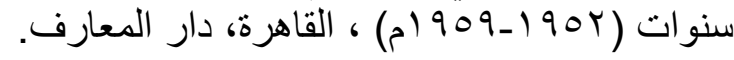

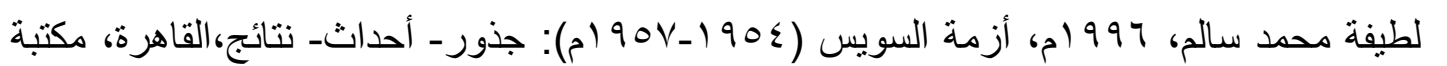
مدبولي. • محمد حسنين هيكل، 919 (م، الطبعة الأولي، ملفات السويس: حرب الثلاثين سنة،القاهرة، مؤسسة الأهر ام للترجمة و النشر.

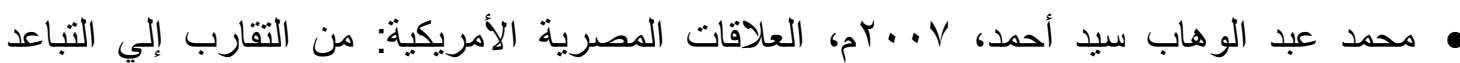

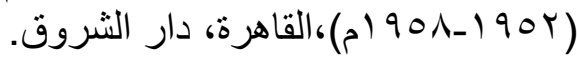

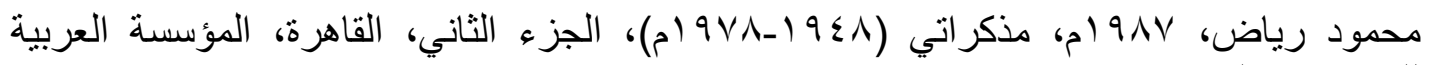
اللار اسات و النشر.

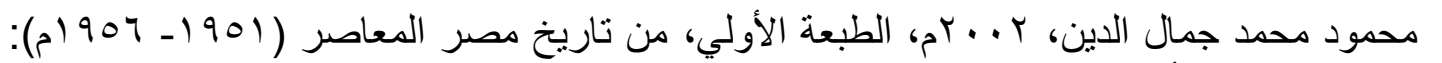
عرض تحليلي للأحداث، القاهرة، دار الفكر العربي.

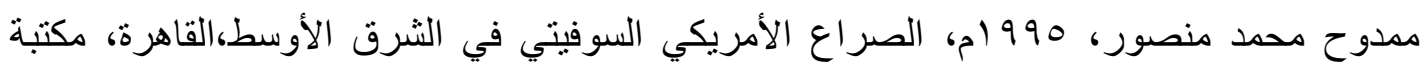
مدبولي.

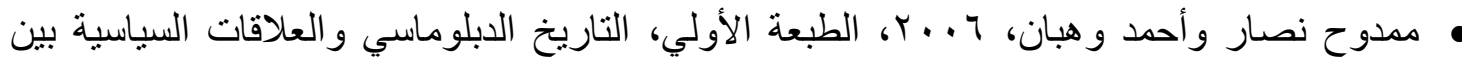

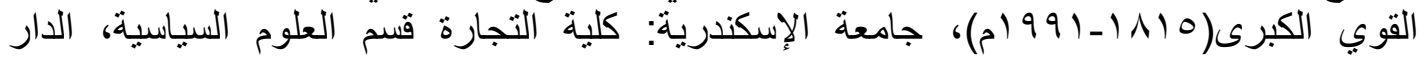
الجامعية للطباعة والنثر و التوزيع. 


\title{
قائمة المراجع الأجنبية
}

- John S. badeau, 1968, the American approach to the Arab world, New York, Harper and Row publishing.

-Philip W. Thayer, 1958, Tension in the Middle East, (Baltimore U.S, john Hopkins press.

-Stanley Hoffmann, 1980, Primacy of World Order: American Foreign Policy since the cold War, U.S, McGrew publishing.

-US National Security Council files, Statement of policy by the national Security Council, Washington, July 14, 1953, Top secret, archive NO. NSC 155/1.

- Department of state official web site, access Date (January 18, 2016).

WWW.m.state.gov

$$
\begin{aligned}
& \text { •الموقع الإلكتروني الرسمي للرئيس جمال عبد الناصر، مجموعة خطب وتصريحات- } 1900 . \\
& \text { www.nasser.bibalex.org } \\
& \text { • الموقع الرسمي لجامعة الدول العربية. } \\
& \text { www.lasportal.org }
\end{aligned}
$$

\section{Egypt and Baghdad pact}

\author{
Mohamed Elkeblawy $^{1}$ Noha Azmy ${ }^{1}$ Mohamed Elemam $^{2}$ \\ ${ }^{1}$ Faculty of Tourism and Hotels, University of Sadat City \\ ${ }^{2}$ Faculty of Arts, Damanhur University
}

\begin{abstract}
After 23 July 1952 revolution, Egypt had a prominent role in confronting the Western military alliances in the Middle East which the United States and the Western powers had set up to counter the Soviet Union ambitions in the region, the research discuss the American defense strategy in the region and how it turned from relying on Suez base as the main base for defend of the Middle East As a result of Egyptian refusal to participate in the military alliances which consider it a kind of new colonialism to move to which called the northern tie countries (Iraq Turkey - Pakistan) as more receptive countries to the idea of participation in military alliances projects which lead finally to the Baghdad pact formation In 1955. the research discuss also how was the Egyptian role towards United States and Britain policies in the region and how Egypt acted on its own to fight Baghdad pact by directing the liberal appeals to the Arab people through Radio Sawt al-Arab which received wide response, also Egypt held alliances with Arab countries like Syria, Saudi Arabia, Jordan and Yemen to form an opposition front against Baghdad pact to prevent any other Arab country to join Baghdad pact except Iraq which hosts the pact Headquarters itself.
\end{abstract}

Keywords: Suez base, Baghdad pact, The middle east, Egypt. 